ARTICLE

https://doi.org/10.1038/s41467-021-27294-5

\title{
SPEN is required for Xist upregulation during initiation of $X$ chromosome inactivation
}

Teresa Robert-Finestra (10) 1, Beatrice F. Tan (10 1,6, Hegias Mira-Bontenbal 1,6, Erika Timmers 1,6, Cristina Gontan ${ }^{1}$, Sarra Merzouk ${ }^{1}$, Benedetto Daniele Giaimo², François Dossin (10 3, Wilfred F. J. van IJcken (1) 4, John W. M. Martens (iD ${ }^{5}$, Tilman Borggrefe ${ }^{2}$, Edith Heard (iD ${ }^{3} \&$ Joost Gribnau (iD) ${ }^{\text {幽 }}$

At initiation of $X$ chromosome inactivation $(\mathrm{XCl})$, Xist is monoallelically upregulated from the future inactive $\mathrm{X}(\mathrm{Xi})$ chromosome, overcoming repression by its antisense transcript Tsix. $X$ ist recruits various chromatin remodelers, amongst them SPEN, which are involved in silencing of X-linked genes in cis and establishment of the Xi. Here, we show that SPEN plays an important role in initiation of $\mathrm{XCl}$. Spen null female mouse embryonic stem cells (ESCs) are defective in Xist upregulation upon differentiation. We find that Xist-mediated SPEN recruitment to the $\mathrm{Xi}$ chromosome happens very early in $\mathrm{XCl}$, and that SPEN-mediated silencing of the Tsix promoter is required for Xist upregulation. Accordingly, failed Xist upregulation in Spen-/- ESCs can be rescued by concomitant removal of Tsix. These findings indicate that SPEN is not only required for the establishment of the $\mathrm{Xi}$, but is also crucial in initiation of the $\mathrm{XCl}$ process.

\footnotetext{
${ }^{1}$ Department of Developmental Biology, Erasmus University Medical Center, Oncode Institute, 3015GD Rotterdam, The Netherlands. ${ }^{2}$ Institute of Biochemistry, University of Giessen, 35392 Giessen, Germany. ${ }^{3}$ European Molecular Biology Laboratory, Director's Research, 69117 Heidelberg, Germany. ${ }^{4}$ Center for Biomics, Erasmus University Medical Center, 3015CN Rotterdam, The Netherlands. ${ }^{5}$ Department of Medical Oncology, Erasmus MC Cancer Institute and Cancer Genomics Netherlands, Erasmus University Medical Center, 3015CN Rotterdam, The Netherlands. ${ }^{6}$ These authors contributed equally: Beatrice F. Tan, Hegias Mira-Bontenbal, Erika Timmers. 凶email: j.gribnau@erasmusmc.nl
} 
T o compensate for gene-dosage imbalance between females (XX) and males (XY), female placental mammals randomly inactivate one $\mathrm{X}$ chromosome early during embryonic development ${ }^{1}$. In mice, random $\mathrm{X}$-chromosome inactivation (XCI) takes place in the epiblast in three phases: initiation, establishment, and maintenance. During the initiation phase, the long noncoding RNA (lncRNA) Xist is upregulated from the future inactive $\mathrm{X}(\mathrm{Xi})$ chromosome ${ }^{2-4}$. Xist is located within the X Chromosome Inactivation Centre (Xic), an X-linked region required for XCI that contains different cis-regulatory elements, including Tsix, another IncRNA gene that is transcribed antisense to and completely overlaps Xist $t^{5}$. Tsix negatively regulates Xist expression via antisense transcription and chromatin remodeling ${ }^{6-12}$. Together, Xist and Tsix form a master switch that controls initiation of XCI: in the pluripotent state, Tsix is biallelically expressed, repressing both alleles of Xist, while upon initiation of XCI, the balance changes, resulting in downregulation of Tsix and upregulation of Xist on the future Xi. Trans-regulators including pluripotency factors OCT4, NANOG, REX1 as well as XCI activators are key in controlling this switch by regulating Xist and Tsix transcription (reviewed in ${ }^{13}$ ). Later, during the establishment phase of XCI, the $17 \mathrm{~kb}$ lncRNA Xist spreads in cis along the future $\mathrm{Xi}$ and recruits different proteins involved in gene silencing that render the $\mathrm{X}$ transcriptionally inactive (reviewed in ${ }^{14}$ ). Active histone marks (H3K4me2/me3, $\mathrm{H} 3$ and $\mathrm{H} 4$ acetylation) are removed and repressive histone marks are instigated, catalyzed by polycomb group complexes and other protein complexes (reviewed $\mathrm{in}^{15}$ ). Finally, in the maintenance phase, the inactive state of the $\mathrm{Xi}$ is epigenetically propagated across cell divisions.

Different studies consisting of Xist RNA immunoprecipitations coupled to mass spectrometry ${ }^{16-18}$ and genetic screens ${ }^{19,20}$ identified SPEN (also known as SHARP in human and MINT in mouse) as a crucial factor in the establishment phase of XCI. SPEN is a large protein with four N-terminal RNA recognition motifs (RRM) and a highly conserved C-terminal SPOC domain able to recruit different proteins involved in transcriptional silencing ${ }^{21,22}$. SPEN is also involved in the Notch signaling pathway and nuclear receptor signaling, where it acts as a transcriptional corepressor ${ }^{23,24}$.

SPEN is crucial for X-linked gene silencing ${ }^{16,17,19,20}$ by binding the Xist repeat $\mathrm{A}(\mathrm{RepA})$ via its RRM domains ${ }^{17,19}$ and interacting via its SPOC domain with the corepressors NCoR/SMRT to recruit/activate histone deacetylase 3 (HDAC3), responsible for the removal of histone $\mathrm{H} 3$ and $\mathrm{H} 4$ acetylation at promoters and enhancers of genes located on the future $\mathrm{Xi}^{16,25}$. Despite this crucial role for SPEN in establishment of the Xi, these studies did not report defects in Xist upregulation and coating $16,17,19,20,25$, possibly due to forced Xist upregulation using doxycyclineinducible systems (Supplementary Table 1).

Here, we show that SPEN accumulates on the Xi very early during differentiation and is required for Xist upregulation. We show that SPEN has a dual function, required to silence Tsix and facilitate Xist upregulation, and stabilization of Xist RNA. Together, our results indicate that SPEN is not only necessary for $\mathrm{X}$-linked gene silencing, but also plays a crucial earlier role in the regulation of initiation of XCI.

\section{Results}

SPEN is required for Xist upregulation. Previous work has shown how SPEN is crucial for silencing of $\mathrm{X}$-linked genes, but these studies did not investigate the role of SPEN in initiation of Xist expression. Therefore, we generated Spen homozygous $\left(\mathrm{Spen}^{-1-}\right)$ and heterozygous $\left(\right.$ Spen $\left.^{+-}\right)$knockout mouse embryonic stem cells (ESCs) by deleting the complete open-reading frame (ORF) using the CRISPR/Cas9 technology (Supplementary Fig. 1a). These lines were generated in a hybrid F1 129/Sv:Cast/EiJ (129/Cast) genetic background with a doxycycline-responsive endogenous Xist promoter located on the Cast X chromosome ${ }^{26}$ (Fig. 1a). The Spen ORF deletion was verified by PCR on genomic DNA (gDNA) and Western blot analysis (Supplementary Fig. 1b,c). Allele-specific RNA-seq analysis (Supplementary Fig. 1d) of wild-type (Wt) undifferentiated ESCs (day 0) containing the doxycycline-responsive Xist promoter treated with and without doxycycline for 4 days showed skewed X-linked gene silencing toward the Cast allele (Fig. 1b, Supplementary Fig. 1e top left). On the other hand, the same analysis in Spen ${ }^{-1-}$ ESCs showed impaired X-linked gene silencing (Fig. 1b, Supplementary Fig. 1e bottom left), as described before ${ }^{16,17,19,20}$ (Supplementary Table 1).

To trigger XCI in the context of differentiation, we forced Xist upregulation by doxycycline treatment followed by monolayer differentiation. Allele-specific RNA-seq analysis of Wt and Spen ${ }^{-1-}$ ESCs treated with doxycycline at day 7 of monolayer differentiation (Supplementary Fig. 1d) also revealed a lack of X-linked gene silencing along the entire $\mathrm{X}$ chromosome (Fig. 1b, Supplementary Fig. 1e bottom right). Similarly, allele-specific RT-qPCR analysis of the X-linked gene Rnf12 revealed impaired silencing (Fig. 1c). Although previous work indicated that in Spen ${ }^{-1}$ ESCs, a group of lowly expressed X-linked genes are susceptible to SPENindependent gene silencing ${ }^{27}$, our RNA-seq analysis shows no silencing of this specific group of genes (Supplementary Fig. 1f,g). We observed Xist upregulation in Wt and Spen ${ }^{-1-}$ cells, however doxycycline induction resulted in lower Xist expression levels in Spen ${ }^{-1-}$ compared with Wt ESCs (Fig. 1d), an effect that was also reported in a recent study ${ }^{27}$.

Next, we recapitulated physiological XCI by monolayer differentiation in the absence of doxycycline to allow normal Xist upregulation and X-linked gene silencing. Allele-specific RNA-seq analysis of Wt and Spen ${ }^{-1-}$ ESCs at day 3 without doxycycline (Supplementary Fig. 1d) shows a significant difference in silencing (Fig. 1b, Supplementary Fig. 1e top right) also visible for Rnf12 at day 3 by RT-qPCR and more pronounced at later time points of differentiation (days 5 and 7) (Fig. 1e). Remarkably, in Spen ${ }^{-1-}$ cells, Xist upregulation from the 129 allele was completely abrogated (Fig. 1f), contrasting earlier evidence that suggested that SPEN is not required for Xist upregulation and coating $16,17,19,20,25$ (Supplementary Table 1). In addition, differentiating Spen ${ }^{-1-}$ ESCs lack Xist clouds, determined by RNA-FISH (Fig. 1g,h), while Tsix was significantly more expressed from the Wt 129 allele in Spen ${ }^{-1-}$ cells compared with Wt cells in differentiating cells (Fig. 1i), suggesting that SPEN might be necessary for Tsix silencing. Importantly, RTqPCR analysis confirmed proper silencing of pluripotency genes Rex1 and Nanog, and upregulation of endoderm marker Gata6 (Supplementary Fig. 1h) in Spen ${ }^{-1-}$ ESCs upon monolayer differentiation, indicating that loss of Xist expression is not related to defective ESC differentiation.

Furthermore, while Spen ${ }^{+/-}$cells are able to upregulate Xist and silence Rnf12 upon doxycycline treatment followed by monolayer differentiation (Supplementary Fig. 2a,b), they show reduced Rnf12 silencing upon physiological differentiation without a defect in Xist upregulation (Supplementary Fig. 2c,d). Given that SPEN levels are reduced in Spen ${ }^{+/-}$cells (Supplementary Fig. 1c), these results demonstrate that SPEN dosage is important in XCI.

Spen rescue leads to normal Xist expression levels. To confirm our results, we performed a rescue experiment by stably reexpressing Spen through introduction of the full-length Spen cDNA in the ROSA26 locus ${ }^{25}$ of Spen $^{-1-}$ ESCs (Supplementary Fig. 3a). 
a
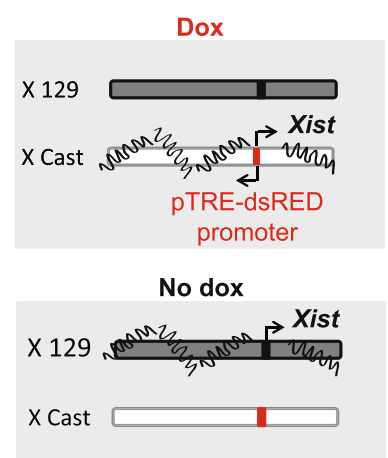

C

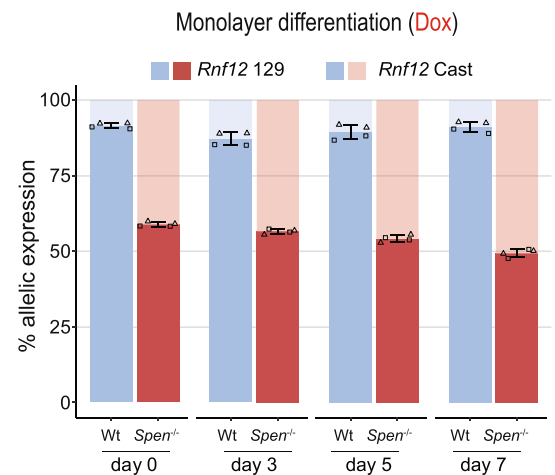

d

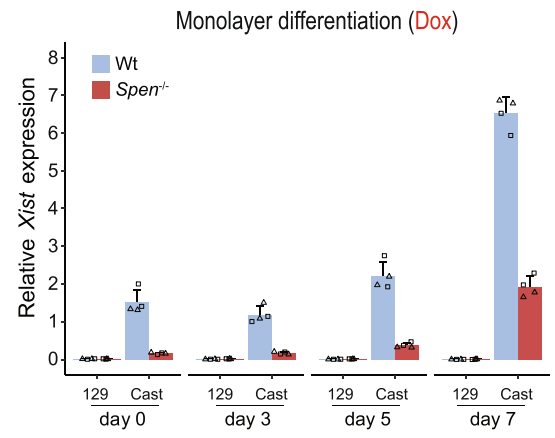

b
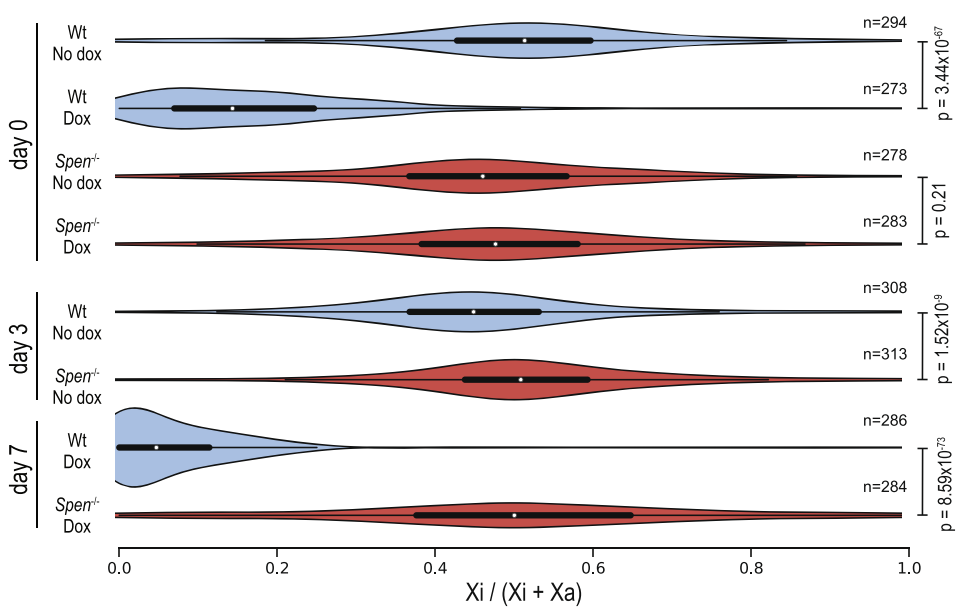

e

Monolayer differentiation (No dox)

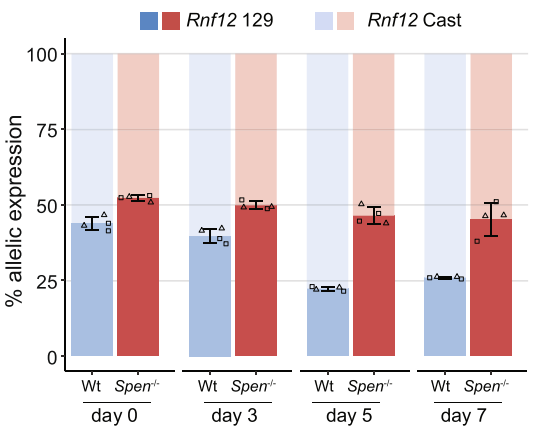

9

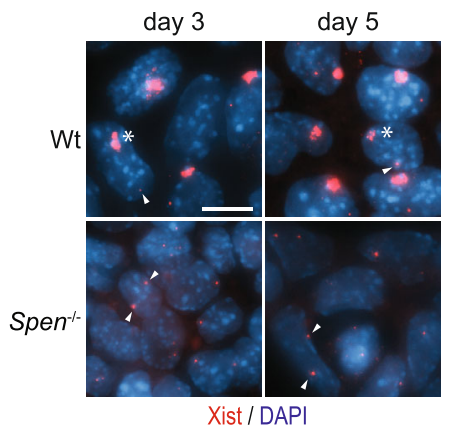

f

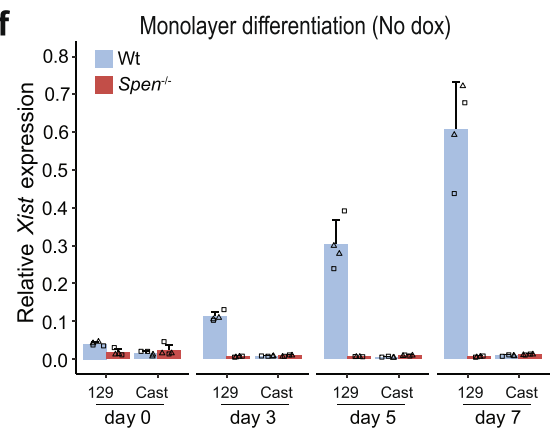

h

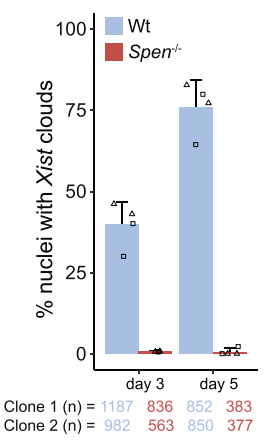

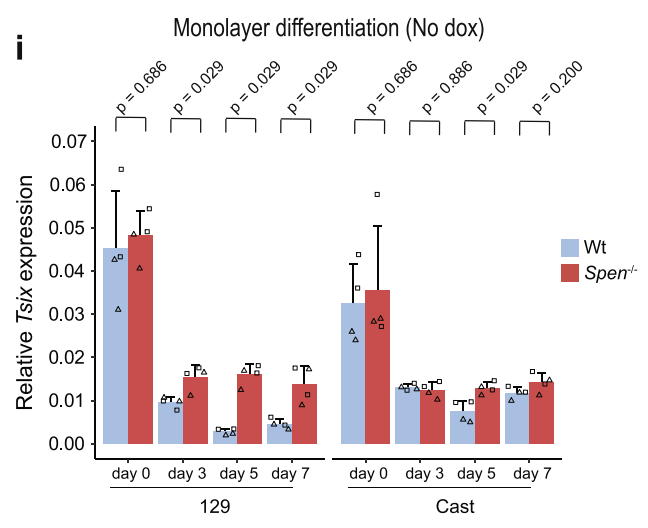

Successful integration was verified by gDNA PCR and confirmed by Spen mRNA and protein levels by RT-qPCR and Western blot, respectively (Supplementary Fig. 3b-d). The generated rescue clones (Clones A, B, and C) display two- to three-fold overexpression of Spen RNA at the ESC stage and during monolayer differentiation (Supplementary Fig. 3c). In contrast to the Spen ${ }^{-1-}$ lines, all Spen ${ }^{-1-(\mathrm{cDNA})}$ rescue clones express Xist at similar levels to $\mathrm{Wt}$ clones during monolayer differentiation (Fig. 2a). Allele-specific expression analysis of Rnf12 and Tsix (129 allele) indicated that the silencing defect is partially rescued in Spen $-/-(\mathrm{cDNA})$ clones (Supplementary Fig. 3e, f). Moreover, RT-qPCR analysis shows silencing of pluripotency markers (Sox2 and Oct4) and upregulation of the endoderm marker Gata6 in the Spen rescue clones (Supplementary Fig. 3g), indicating that Spen overexpression 
Fig. 1 Impaired Xist upregulation in Spen ${ }^{-/}$ESCs upon monolayer differentiation. a Overview of the endogenous doxycycline-inducible Xist hybrid system used in this study. Addition of doxycycline leads to inactivation of the Cast $X$ chromosome, while no addition of the drug leads to inactivation of the 129 X chromosome. $\mathbf{b}$ Violin plots depicting the distribution of the allelic ratios $((X i) /(X i+X a))$ of $X$-linked genes in Wt and Spen ${ }^{-/-}$ESCs, untreated or treated with doxycycline at days 0,3 , and 7 of differentiation. This figure summarizes data in Supplementary Fig. 1e. The box plots inside the violin plots display the median (central white dot), the interquartile range (box limits) and the whiskers represent 1.5x of the interquartile range. Two-sided Mann-Whitney test corrected with Benjamini-Hochberg for multiple testing $(\alpha<0.05) . n=$ genes with more than 20 reads. Xa=active $X$ chromosome. c Percentage of Rnf12 allelic expression at different time points of monolayer differentiation of two independent Wt and Spen-/- ESC lines treated with doxycycline, determined by RT-qPCR. Relative Rnf12 allelic (129 and Cast) expression was normalized to Rnf12 total expression and averaged \pm standard deviation (SD). Reference gene: Hist2h2aa1. d Relative allele-specific Xist expression of two independent Wt and Spen-/- ESC lines at different time points of monolayer differentiation treated with doxycycline. Average expression \pm SD. Reference gene: Hist2h2aa1. e Same as displayed in (c) without doxycycline. $\mathbf{f}$ Same as displayed in (d) without doxycycline. $\mathbf{g}$ Xist RNA FISH (red) of Wt and Spen ${ }^{-/}$- ESC lines at days 3 and 5 of differentiation. Both Tsix pinpoints (arrowheads) and Xist clouds (asterisks) are visible. DNA is stained with DAPI (blue). Scale bar: $10 \mu \mathrm{m}$. $\mathbf{h}$ Quantification of ( $\mathbf{g}$ ), displaying the average percentage of nuclei with Xist clouds. Average percentage \pm SD, the total number of counted nuclei per clone is indicated. $\mathbf{i}$ Relative allele-specific Tsix expression of $\mathrm{Wt}$ and Spen ${ }^{-/-}$ESCs at different time points of monolayer differentiation, determined by RT-qPCR. Average expression \pm SD. Twosided Mann-Whitney test $(\alpha<0.05)$. Reference gene: Hist2h2aa1. $(\mathbf{c}-\mathbf{f}, \mathbf{h}, \mathbf{i}) n=4$ biological replicates including 2 independent clones (squares vs. circles) per condition.

a

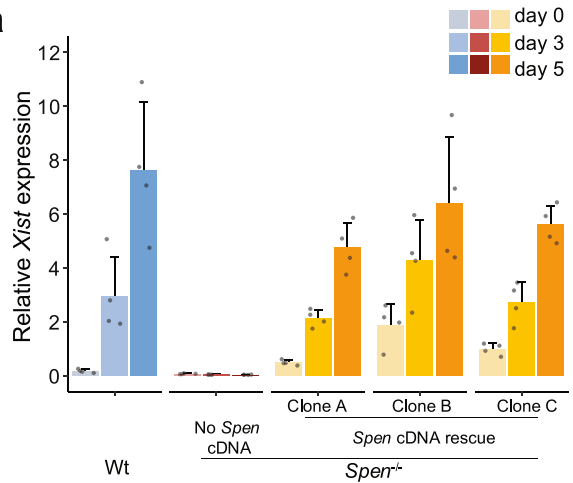

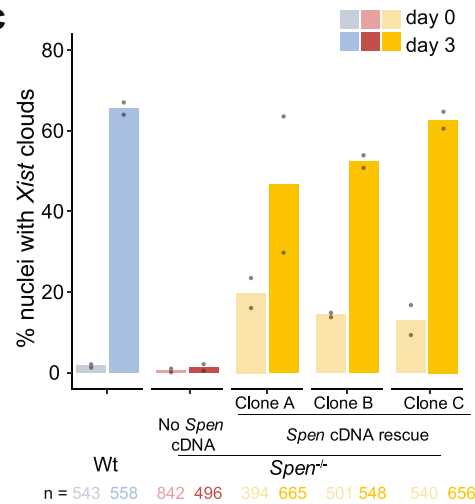

b

Wt

Spen $^{-1}$

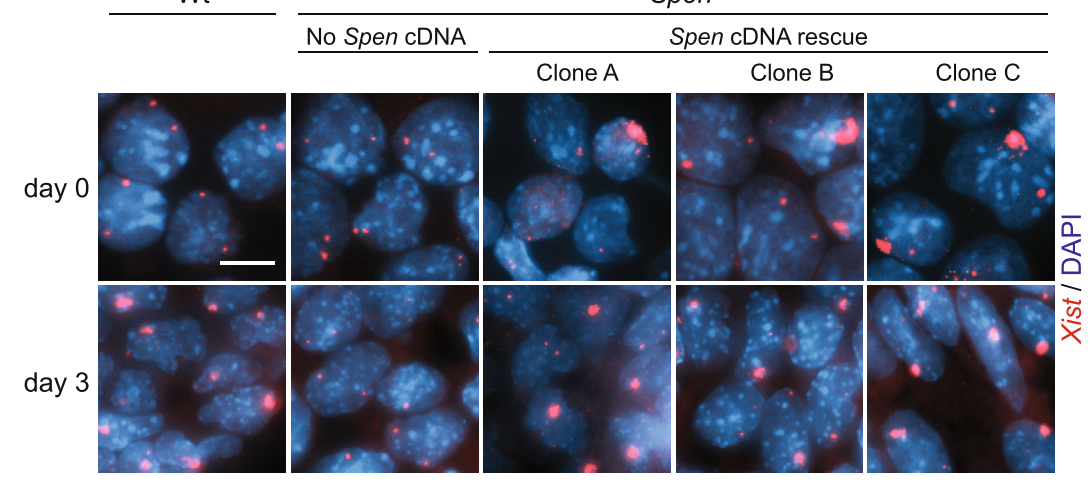

Fig. 2 Spen cDNA expression in Spen ${ }^{-/-}$ESCs rescues Xist expression. a Relative total Xist expression determined by RT-qPCR at days 0,3 , and 5 of monolayer differentiation of Wt, Spen ${ }^{-/-}$and three independent rescue clones (Clone A, B and C). Average expression \pm SD, $n=4$ biological replicates per condition. Reference gene: Hist2h2aa1. b RNA FISH of Xist (red) at days 0 and 3 of monolayer differentiation of Wt, Spen ${ }^{-1-}$, and Spen rescue clones. DNA stained with DAPI (blue). Scale bar: $10 \mu \mathrm{m}$. c Quantification of (b), showing the percentage of nuclei with Xist clouds in each condition. Average percentage, $n=2$ biological replicates, the total number of counted nuclei is indicated.

does not cause a differentiation phenotype. Interestingly, in undifferentiated Spen ${ }^{-1-(c D N A)}$ ESC clones, Xist levels were higher than in Wt controls (Fig. 2a), and Xist RNA-FISH analysis revealed a significant percentage of Spen ${ }^{-1-(\mathrm{cDNA})}$ undifferentiated ESCs having Xist clouds (Fig. 2b, c), probably due to higher SPEN abundance after overexpression in the undifferentiated state (Supplementary Fig. 3c).

SPEN accumulation on the Xi early during XCI. In light of the previous results, we expect SPEN to accumulate on the $\mathrm{Xi}$ at the very early steps of physiological XCI. To investigate this hypothesis and since commercial SPEN antibodies suitable for immunofluorescence (IF) are lacking, we generated ESCs endogenously expressing a C-terminally tagged SPEN-GFP (Supplementary Fig. 4a). Correct GFP integration was confirmed by PCR on gDNA and by FACS analysis (Supplementary Fig. 4b,c). IF detection of GFP at different time points of monolayer differentiation revealed SPEN accumulation as early as day 1 in about $30 \%$ of the nuclei (Fig. 3a, b). This percentage remained stable until day 3, while from day 5 onward, SPEN accumulation increased to plateau at day 7. Interestingly, the intensity of SPENGFP accumulations gradually rises as differentiation progresses (Fig. 3c), suggesting that the number of SPEN molecules increases over time. 

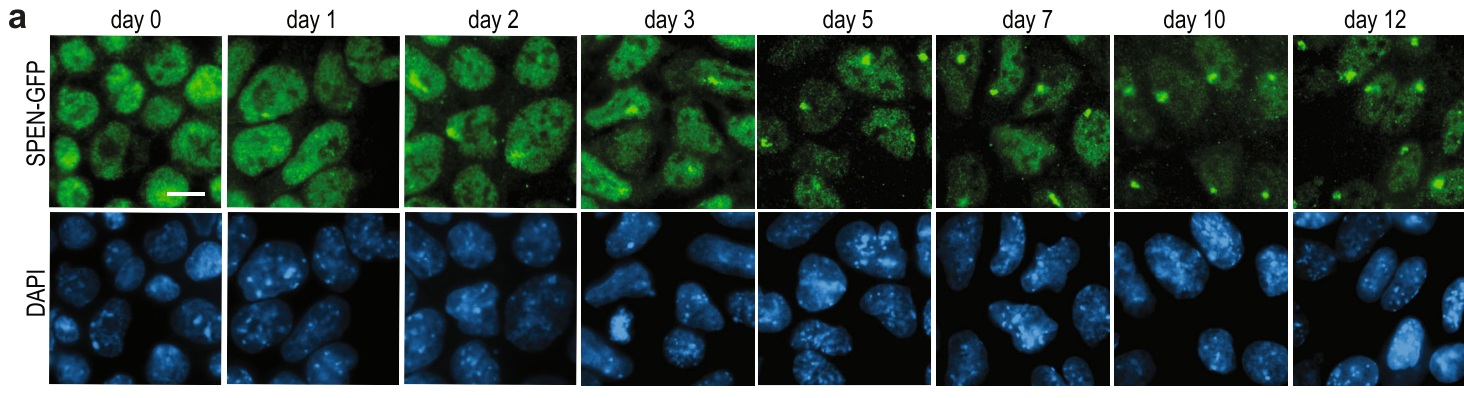

b

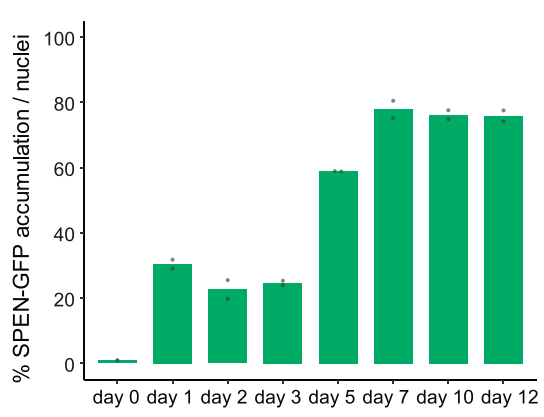

$\begin{array}{llllllll}\text { Clone } 1(n)=313 & 261 & 239 & 371 & 173 & 226 & 215 & 205 \\ \text { Clone 2 }(n)=232 & 230 & 278 & 363 & 209 & 174 & 268 & 124\end{array}$

C

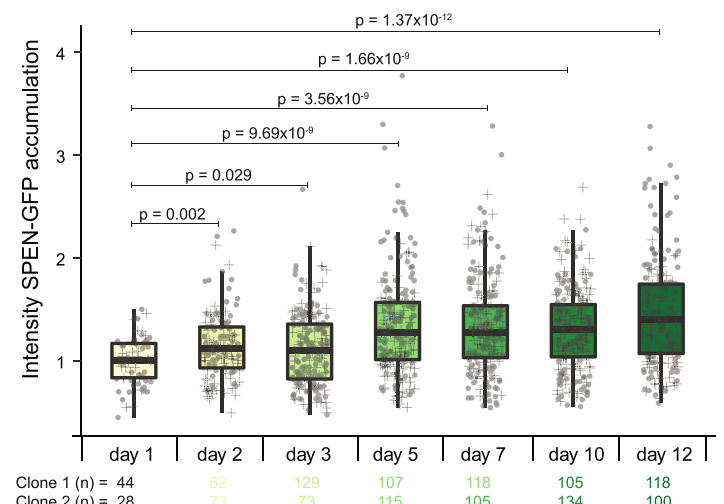

d

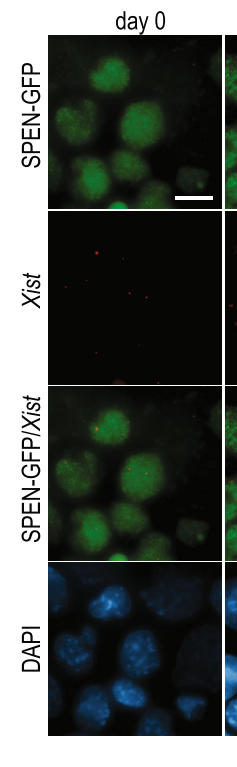

e

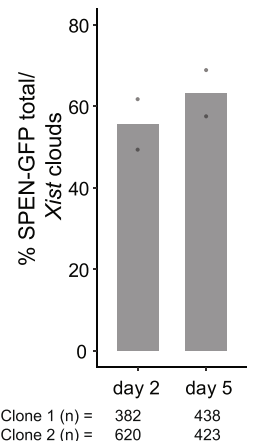

day 2

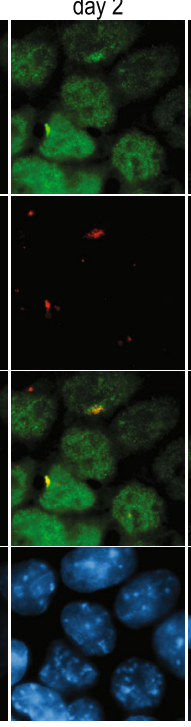

f

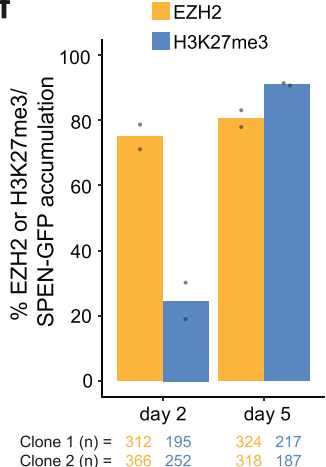

Fig. 3 SPEN colocalizes with the Xi chromosome very early during monolayer differentiation. a SPEN-GFP IF staining ( $\alpha$ GFP, green) at different time points of monolayer differentiation (day $0,1,2,3,5,7,10$, and 12). DNA is stained with DAPI (blue). Scale bar: $10 \mu \mathrm{m}$. b Quantification of (a), depicting the percentage of SPEN-GFP accumulation per nuclei at different time points of monolayer differentiation. Average percentage, $n=2$ independent clones, the total number of counted nuclei per clone is indicated. c Boxplots illustrating the intensity of SPEN-GFP accumulations at different days of monolayer differentiation. The box plots display the median (central black line), the interquartile range (box limits) and the whiskers represent $1.5 x$ of the interquartile range. All the data points are shown for two independent SPEN-GFP clones (filled circles vs. crosses). Two-sided Mann-Whitney test corrected with Benjamini-Hochberg for multiple testing $(\alpha<0.05)$. The total number of studied nuclei per clone is indicated. $\mathbf{d}$ IF ( $\alpha$ GFP, green) combined with Xist RNA FISH (red) of SPEN-GFP lines at days 0,2 , and 5 of monolayer differentiation. DNA is stained with DAPI (blue). Scale bar: $10 \mu \mathrm{m}$. e Percentage of nuclei with a Xist cloud that also presents SPEN accumulation. Average percentage, $n=2$ independent clones, the total number of counted nuclei per clone is indicated. Calculated from the same data as for Supplementary Fig. 4d. f Percentage of nuclei with SPEN accumulation that also present EZH2 or H3K27me3 accumulation. Average percentage, $n=2$ independent clones, the total number of counted nuclei per clone is indicated. Calculated from the same data as for Supplementary Fig. $4 g$.

Previous studies have shown that SPEN and Xist colocalize in doxycycline-inducible Xist undifferentiated ESC lines ${ }^{20,25}$, although the normal timing and relationship between SPEN and Xist in differentiating cells remained unexplored. Therefore, we investigated SPEN accumulation in relation to Xist, by performing GFP IF combined with Xist RNA FISH in differentiating cells (Fig. 3d, Supplementary Fig. 4d). This analysis indicated that at day 2 of differentiation, about $55 \%$ of the cells with Xist clouds showed SPEN colocalization (Fig. 3e).

We also studied the relation of SPEN with other key players in $\mathrm{XCI}$, including the PRC2 catalytic subunit EZH2 and its catalytic product H3K27me3. As found for Xist, we could detect colocalization of EZH2 and its associated histone modification with SPEN (Supplementary Fig. 4e-g). At day 2 of differentiation, 
a

mESCs,

day 0 (Dox)

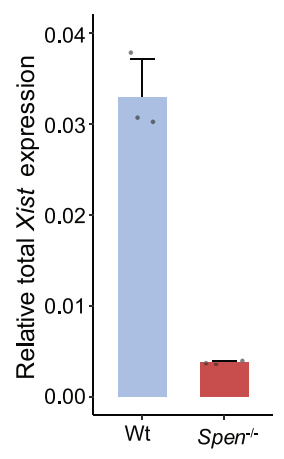

b

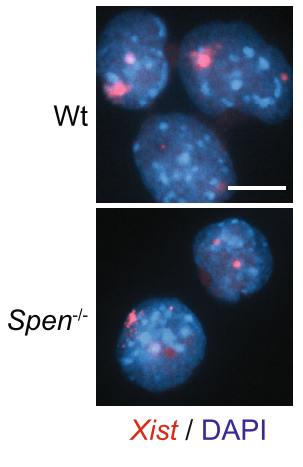

C

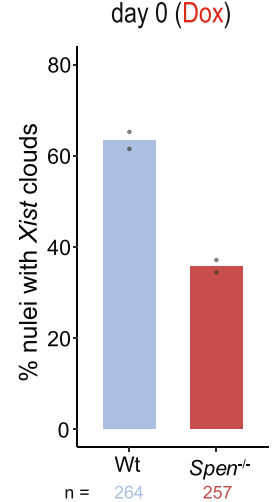

d

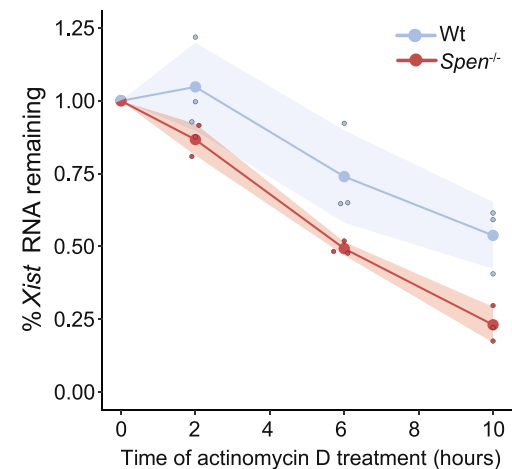

Fig. 4 SPEN plays a role in Xist RNA stability. a Relative total Xist expression in undifferentiated Wt and Spen ${ }^{-/-}$ESCs upon Xist induction with doxycycline for 4 days. $n=3$ biological replicates per condition. Average expression \pm SD. Reference gene: Beta-actin. b Xist RNA FISH (red) of undifferentiated Wt and Spen ${ }^{-1-}$ ESCs treated with doxycycline to induce Xist expression. DNA is stained with DAPI (blue). Scale bar: $10 \mu \mathrm{m}$. c Quantification of (b), displaying the percentage of nuclei with Xist clouds. Average percentage, $n=2$ biological replicates per condition, the total number of counted nuclei is indicated. d Percentage of Xist RNA remaining at different time points of actinomycin D treatment $(t=0,2,6$ and $10 \mathrm{~h})$ in undifferentiated Wt and Spen ${ }^{-/-}$ESCs treated with doxycycline. Normalized relative expression to $t=0 \pm S D$, shading represents the SD, $n=3$ biological replicates per condition. Reference gene: Beta-actin.

about $70 \%$ of nuclei with SPEN accumulation displayed EZH2 and $20 \% \mathrm{H} 3 \mathrm{~K} 27 \mathrm{me} 3$ accumulation. At day 5, the percentage of nuclei with SPEN accumulation that also have EZH2 or $\mathrm{H} 3 \mathrm{~K} 27 \mathrm{me} 3$ is of approximately $80 \%$ and $90 \%$, respectively (Fig. 3f). Our results show that SPEN accumulation on the Xi happens very early upon differentiation in a progressive manner.

Xist RNA stability is compromised in Spen ${ }^{-/-}$ESCs. We have shown that SPEN is required for endogenous Xist upregulation and XCI upon ESC differentiation. In addition, we noticed that forced Xist upregulation resulted in reduced Xist RNA levels in Spen ${ }^{-1-}$ cells compared with Wt cells (Fig. 1d, Fig. 4a). Accordingly, the percentage of nuclei with Xist clouds was lower in Spen ${ }^{-1-}$ cells with doxycycline-induced Xist versus Wt cells and Xist clouds were in general smaller (Fig. 4b, c), an effect that could be attributed to affected stability of Xist. To study the role of SPEN in Xist stability, we determined the half-life of doxycycline-induced Xist RNA in Spen ${ }^{-1-}$ and Wt ESCs treated with actinomycin $\mathrm{D}$ to block its transcription. The remaining levels of Xist RNA at different time points were assessed by RTqPCR, and the Xist RNA-decay rate and half-life were then calculated (Fig. 4d). In Wt ESCs, the Xist RNA half-life was $10 \mathrm{~h}$ $17 \mathrm{~min}$, whereas the Xist half-life was reduced to $4 \mathrm{~h} 40 \mathrm{~min}$ in Spen $^{-1-}$ cells. These results indicate that SPEN plays a role in Xist RNA stability, but cannot explain why physiological Xist upregulation is lost in $S_{p e n}{ }^{-1-}$ ESCs upon differentiation.

SPEN, HDAC3, and H3K27ac are enriched at the Tsix regulatory region. Our results showed that at late days of monolayer differentiation, Spen ${ }^{-1-}$ cells display higher Tsix levels than control cells (Fig. 1i), suggesting that SPEN might be recruited by Xist to silence Tsix. Hence, we explored SPEN genomic binding at the Xist-Tsix locus using published SPEN CUT\&RUN data in undifferentiated ESCs with a doxycycline-responsive Xist promoter $^{25}$. SPEN accumulation is evident on the gene body of Xist as well as on the Tsix regulatory region at $24 \mathrm{~h}$ of doxycycline induction, but more prominently after 4 and $8 \mathrm{~h}$ of induction (Fig. 5a, b). This Tsix regulatory region comprises the minor and major Tsix promoters and Xite, an enhancer of Tsix ${ }^{28}$. Xistmediated recruitment of SPEN is important for recruitment and/ or activation of HDAC3, responsible for the removal of $\mathrm{H} 3 \mathrm{~K} 27 \mathrm{ac}$ from the future $\mathrm{Xi}^{16,29}$. Analysis of published HDAC3 and H3K27ac ChIP-seq data from undifferentiated female ESCs upon $24 \mathrm{~h}$ of Xist induction ${ }^{29}$ reveals HDAC3 binding and H3K27ac loss at the Tsix regulatory region, where SPEN is recruited (Fig. 5a). Moreover, X-linked Rnf12 (Supplementary Fig. 5a) and Pgk1 (Supplementary Fig. 5b) display SPEN and HDAC3 enrichment at their promoters and $\mathrm{H} 3 \mathrm{~K} 27 \mathrm{ac}$ loss upon Xist induction. Interestingly, $R n f 12$, an early silenced gene ${ }^{30}$, shows SPEN and HDAC3 promoter binding in the undifferentiated state without Xist induction, suggesting that in the undifferentiated state, Xist might be sufficiently expressed at very low levels to partly silence $R n f 12$, explaining the $R n f 12$ allelic ratio difference between Wt and Spen ${ }^{-1-}$ ESCs at day 0 (Fig. 1e, Supplementary Fig. 3e).

To test whether SPEN recruitment leads to H3K27me3 accumulation, we performed H3K27me3 ChIP-seq on Spen ${ }^{-1-}$ and Wt ESCs prior to and during differentiation (day 3) (Fig. 5a). This analysis showed that while Wt cells display H3K27me3 enrichment at the Tsix-regulatory region upon differentiation, Spen ${ }^{-1-}$ cells do not, in accordance with their lack of Xist upregulation. Interestingly, the $\mathrm{H} 3 \mathrm{~K} 27 \mathrm{me} 3$ hotspot, located at the $3^{\prime}$ end of Tsix ${ }^{31,32}$, is clearly reduced upon differentiation both in Wt and Spen ${ }^{-1-}$ cells, while Wt and Spen ${ }^{-1-}$ ESCs show no difference in $\mathrm{H} 3 \mathrm{~K} 27 \mathrm{me} 3$ levels, pointing to a SPEN-independent H3K27me3 enrichment at the hotspot (Fig. 5a). Altogether, these data support a model where Xist-mediated SPEN recruitment leads to Tsix promoter silencing.

SPEN is required to silence Tsix to allow Xist upregulation. To further investigate the role of SPEN in silencing Tsix, we generated compound Spen ${ }^{-1-}$ :Tsix-defective hybrid ESC lines. If Xistmediated recruitment of SPEN to the Tsix regulatory region is crucial for Tsix silencing and Xist upregulation, we expect Xist upregulation upon differentiation to be rescued in these doubleknockout cell lines. We made use of a Tsix-Stop line containing a triple poly(A) signal downstream of the major Tsix promoter that blocks its transcription on the 129 allele $^{7}$, and a Tsix-Cherry line with a mCherry coding sequence introduced downstream of the major Tsix promoter on the Cast allele ${ }^{33}$ (Fig. 6a). As controls, we generated Spen ${ }^{-1-}$ ESCs in the same hybrid background (F1:129/ Cast) where both Xist alleles are intact ${ }^{34}$, in contrast to the previously studied ESCs that contained a doxycycline-inducible Xist 


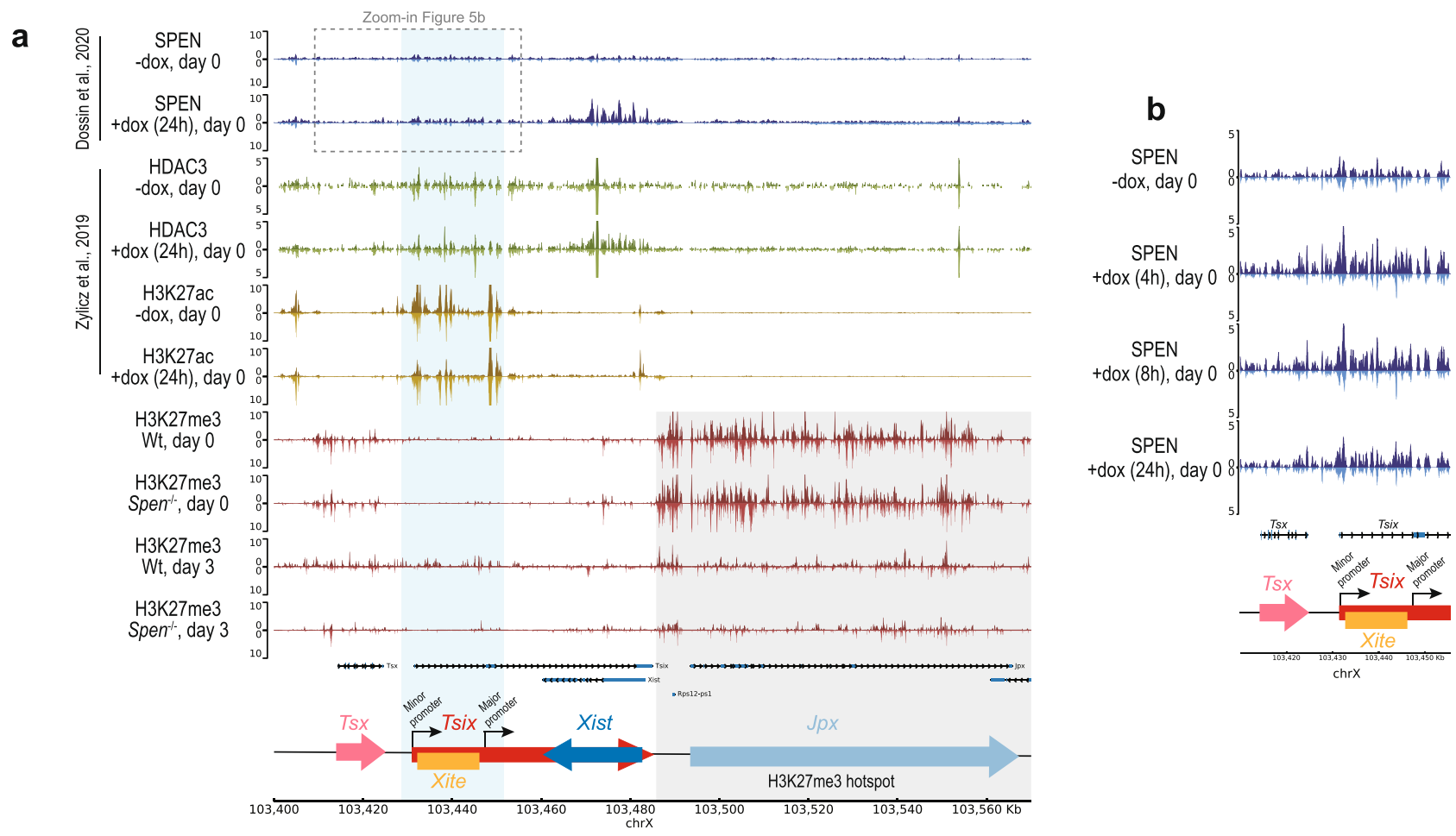

Fig. 5 Tsix-regulatory region shows SPEN, HDAC3 and H3K27ac enrichment. a Genome browser tracks showing allele-specific SPEN, HDAC3, H3K27ac and H3K27me3 binding at the Xist-Tsix locus. The top part (dark) of each track represents the Xi and the bottom (light) the Xa. SPEN CUT\&RUN (blue, top) profile in Xist-inducible undifferentiated ESCs (day 0) untreated or treated with doxycycline ( $24 \mathrm{~h})^{25}$. HDAC3 (green, middle-top) and H3K27ac ChIPseq (yellow, middle-bottom) in Xist-inducible undifferentiated ESC (day 0) untreated or treated with doxycycline $(24 \mathrm{~h})^{29}$. H3K27me3 ChIP-seq (red, bottom) in Wt and Spen-/- ESCs at days 0 and 3 of monolayer differentiation. The light-blue rectangle highlights the Tsix regulatory region, including the Tsix minor and major promoters, and Xite. The light-gray rectangle highlights the H3K27me3 hotspot region. The dashed rectangle indicates the genomic region in (b). b Zoom-in view of the Tsix promoter region, showing the SPEN CUT\&RUN profile in undifferentiated ESCs (day 0) untreated or treated (4 h, $8 \mathrm{~h}$ and $24 \mathrm{~h}$ ) with doxycycline.

allele. Deletion of the Spen ORF was confirmed in all cell lines by PCR on gDNA and Western blot analysis (Supplementary Fig. 6a,b). We generated two independent knockout clones per line. All ESC lines were differentiated in biological quadruplicates, followed by allele-specific Xist RNA expression analysis by RTqPCR. As expected, the F1:129/Cast control Spen ${ }^{-1-}$ line showed no Xist upregulation (Fig. 6b), similar to the phenotype observed in the Spen knockout clones generated in the heterozygous doxycycline-inducible Xist cell line (Fig. 1f). Remarkably, the introduction of a poly(A) signal in Spen ${ }^{-1-}$ :Tsix-Stop lines fully rescued Xist upregulation upon differentiation (Fig. 6c), indicating that SPEN is required for Xist upregulation via Tsix repression. However, the Spen ${ }^{-1-}$ :Tsix-Cherry lines displayed only mild upregulation of Xist upon differentiation (Fig. 6c). These differences in the rescue phenotype between Spen ${ }^{-1-}$ :Tsix-Cherry and Spen ${ }^{-1-}:$ Tsix-Stop lines can be explained by the remaining Tsix transcription in the Tsix-Cherry line, which is fully ablated in the Tsix-Stop lines (Supplementary Fig. 6c). As expected, the Spen ${ }^{-1-}$ : Tsix-Stop lines are not able to silence Rnf12, despite normal Xist levels in the Tsix-Stop line (Supplementary Fig. 6d). Moreover, the Spen ${ }^{-1-}:$ Tsix-Stop lines display Xist clouds that were similar in morphology and number compared with Wt F1:129/ Cast cells (Fig. 6d, e).

Using a doxycycline-inducible Xist line, we have shown SPEN's importance in Xist RNA stability (Fig. 4d). However, since doxycycline-induced Xist expression is about 10 times higher compared with its endogenous expression upon differentiation (Fig. 1d,f), we wanted to analyze the SPEN's role in Xist RNA stability when expressed endogenously. For this, we used Wt: and Spen $^{-1-}$ :Tsix-Stop ESCs at day 3 of monolayer differentiation, where Xist is upregulated from its endogenous promoter (Fig. 6c). In Wt:Tsix-Stop ESCs, Xist RNA's half-life was $9 \mathrm{~h} 42 \mathrm{~min}$, while in Spen ${ }^{-1}:$ :Tsix-Stop ESCs, it was reduced to $2 \mathrm{~h} 46 \mathrm{~min}$ (Fig. 6f), confirming that SPEN is important for Xist RNA stability, independently of the promoter type and RNA abundance.

Taken together, our results indicate an essential role for SPEN in Xist upregulation, mainly via silencing of Tsix, and to a lesser extent by stabilizing Xist RNA. SPEN is therefore not only crucial in X-linked gene silencing but also in the early initiation steps of $\mathrm{XCI}$, playing a role in the feedforward loop leading to Xist activation (Fig. 7).

\section{Discussion}

In this study, we show that SPEN-defective ESCs do not upregulate Xist upon differentiation and study the molecular mechanism behind this observation. To explore the role of SPEN in XCI, various studies used Xist-inducible ESC lines to generate SPEN-knockdown or -knockout cell lines (Supplementary Table 1). Forcing Xist expression in ESCs is a powerful way to understand X-linked gene silencing, but is not suitable to investigate the initiation phase of XCI. Studies exploring the role of SPEN in cells undergoing physiological XCI involved Spen knockdown strategies ${ }^{17,20}$, therefore, the levels of SPEN might have been sufficient to allow normal Xist upregulation, while showing a defect in X-linked gene silencing. Likewise, our Spen ${ }^{+/-}$ ESC lines show Xist upregulation, but reduced X-linked silencing compared with Wt lines. In agreement with our results, one study reports lower Xist abundance and cloud formation upon forced Xist induction from the endogenous locus in $\mathrm{Spen}^{-1-} \mathrm{ESCs}^{27}$. Another recent study suggested that Spen ${ }^{-1-}$ ESCs are not able to 
a

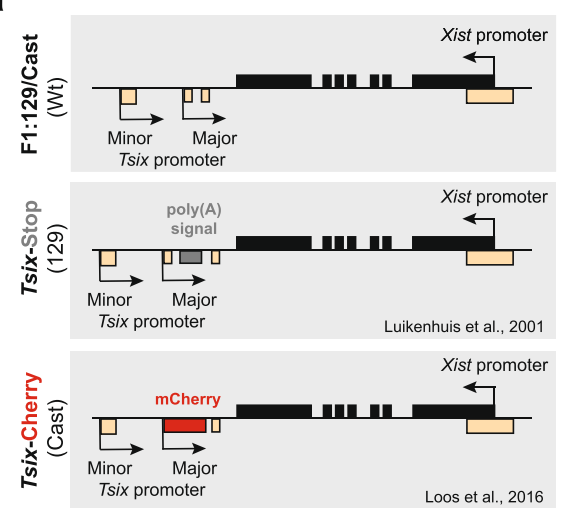

C

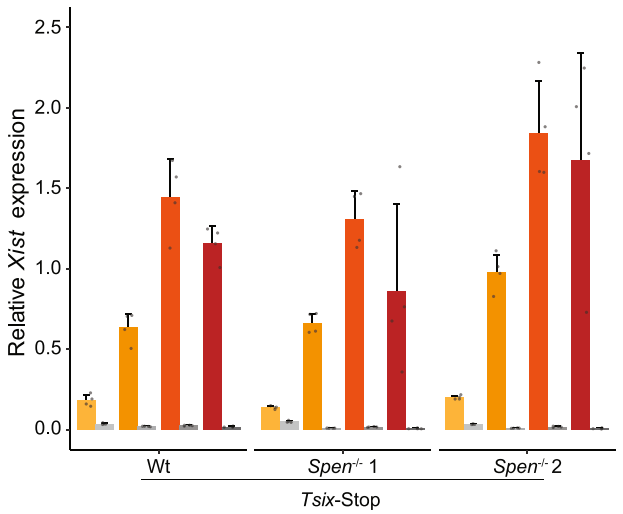

d

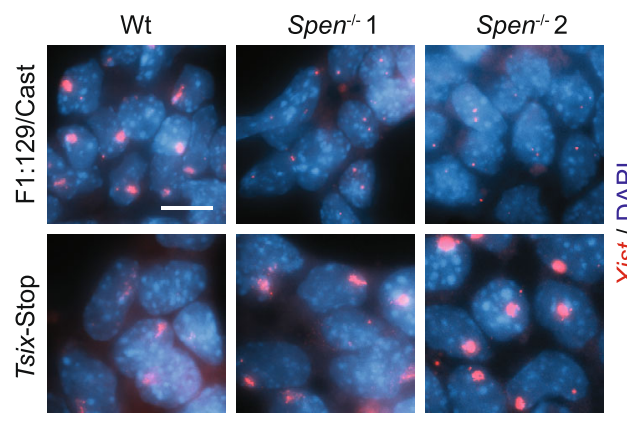

day 3 b

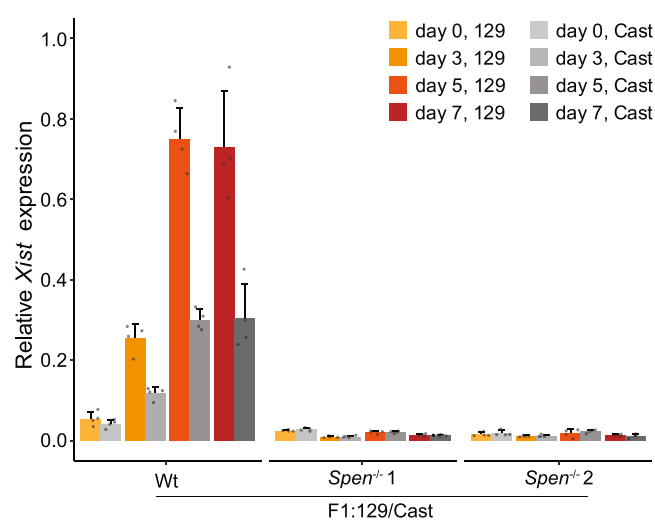

day 0,129 day 0 , Cast

day 3,129 day 3 , Cast

day 5,129 day 5 , Cast

day 7,129 day 7 , Cast

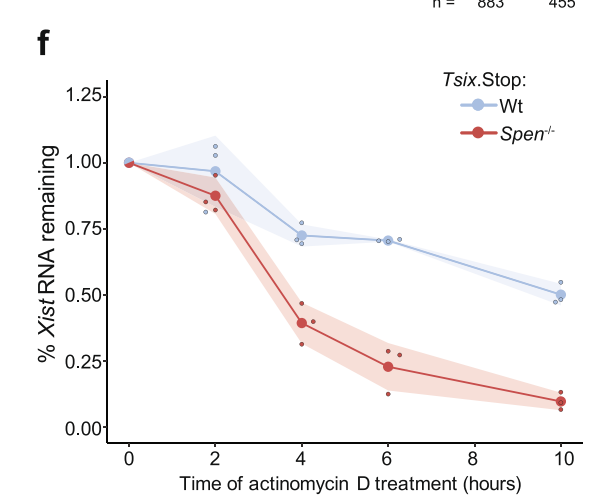

differentiate upon leukemia inhibitory factor (LIF) removal and differentiation towards neural progenitor cells ${ }^{35}$, while we observe that Spen $^{-1-}$ ESCs display a normal morphology in the undifferentiated state and undergo normal differentiation upon monolayer differentiation. Nevertheless, we observe more cell death of Spen ${ }^{-1-}$ cells compared with Wt cells upon monolayer differentiation, although we consider that this might not be XCI- related since X0 Spen ${ }^{-1-}$ cells also die upon differentiation (data not shown). This observation is probably not surprising since SPEN plays a role in various biological processes as a transcriptional repressor ${ }^{23,24,36}$.

Previous studies performed with doxycycline-inducible Xist lines show that SPEN and Xist colocalize soon after Xist induction ${ }^{20,25}$. However, Xist upregulation from a doxycycline- 
Fig. 6 SPEN is required to silence Tsix, to allow Xist upregulation upon $\mathbf{X C I}$ initiation. a Schematic overview of the Tsix-defective ESC lines used to study the role of SPEN in Tsix silencing and Xist upregulation, namely, Wt (F1:129/Cast) (top), Tsix-Stop (middle), and Tsix-Cherry (bottom). The Tsix-Stop line is defective for Tsix in the 129 allele; the Tsix-Cherry line is defective in the Cast allele. Homozygous deletion of Spen was performed in the three lines. b Relative allele-specific Xist expression in Wt and Spen-/- F1:129/Cast ESC lines at different time points of monolayer differentiation. Average expression $\pm \mathrm{SD}, n=4$ biological replicates per condition. Reference gene: Hist2h2aa1. c Same as in (b) for Wt and Spen ${ }^{-/-}$Tsix-Stop and Tsix-Cherry ESC lines. $\mathbf{d}$ Xist RNA FISH (red) at day 3 of monolayer differentiation in F1:129/Cast and Tsix-Stop Wt and Spen ${ }^{-/-}$ESC lines. DNA is stained with DAPI (blue). Scale bar: $10 \mu \mathrm{m}$. e Quantification of (d), showing the percentage of nuclei with Xist clouds. Average percentage, $n=2$ biological replicates per condition, the total number of counted nuclei is indicated. $\mathbf{f}$ Percentage of Xist RNA remaining at different time points of actinomycin $\mathrm{D}$ treatment $(t=0,2,4,6$, and $10 \mathrm{~h})$ in differentiating Wt and Spen ${ }^{-/}$Tsix-Stop ESCs (day 3). Normalized relative expression to $t=0 \pm S D$, shading represents the SD, $n=3$ biological replicates. Reference gene: Beta-actin.

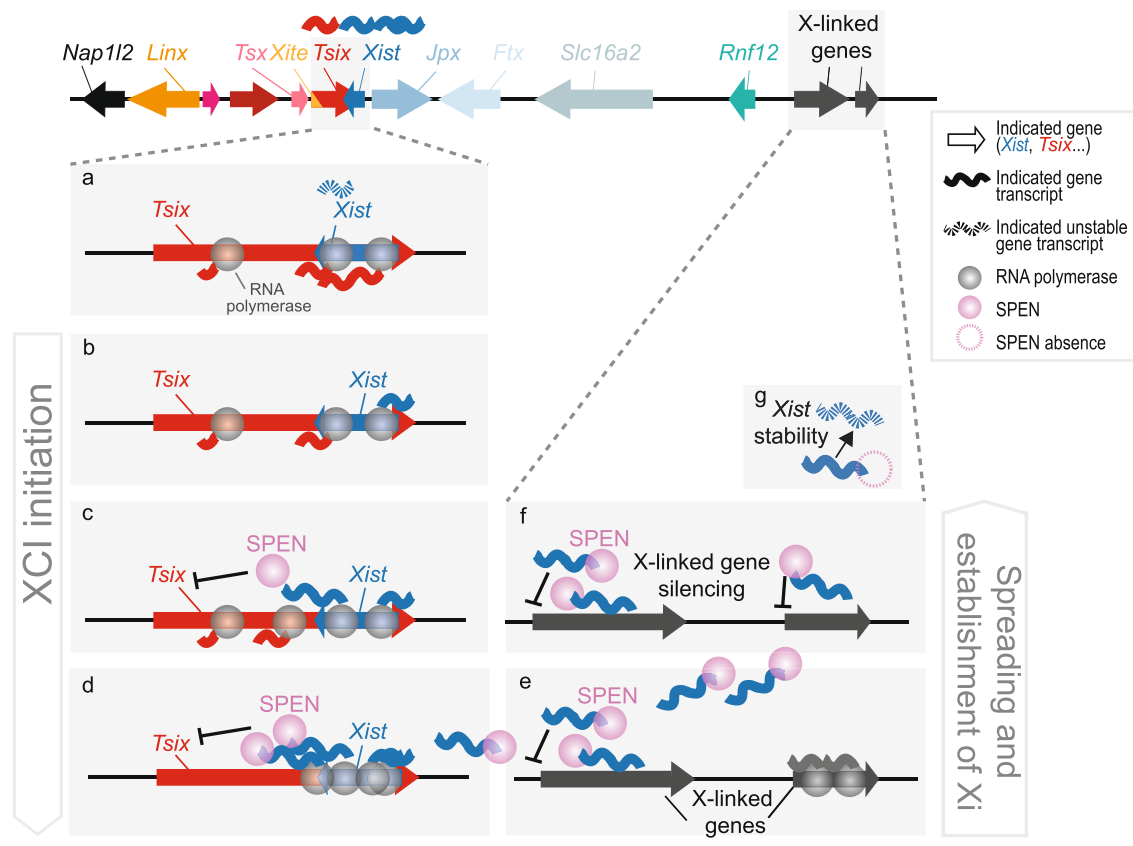

Fig. 7 Model of the role of SPEN in XCI. In the undifferentiated state, Tsix transcription represses Xist and Tsix RNA levels are high (a). Upon differentiation, at the start of $\mathrm{XCl}(\mathbf{b}-\mathbf{d})$, Xist transcription increases (b), the nascent Xist transcripts recruit SPEN that is necessary to silence the Tsix promoter through removal of active H3K27ac marks (c). Consequently, the silencing of Tsix allows Xist upregulation and accumulation (d). Later, during the establishment phase of $\mathrm{XCl}$, the spreading of SPEN-Xist along the $X$ chromosome allows the silencing of active genes (e, $\mathbf{f}$ ). Moreover, SPEN is also necessary to stabilize Xist RNA (g). This model, in addition to previous evidence, proposes that SPEN is not only key in X-linked gene silencing, but also in initiation of $\mathrm{XCl}$.

inducible promoter happens at a very different timescale than during physiological XCI. In the present study, we observe that cells with SPEN accumulation are detectable from day 1 of differentiation with their number and intensity levels of these accumulations increasing over time, suggesting that SPEN accumulates in a progressive manner.

In addition, we provide evidence that SPEN is required to silence Tsix to allow Xist upregulation. (I) In Spen ${ }^{-1-}$ cells, we detect higher levels of Tsix in differentiating cells from the allele undergoing $\mathrm{X}$-chromosome inactivation, compared with $\mathrm{Wt}$ cells. In line with this, paternal Tsix levels in female E3.5 blastocysts with a mutated Xist RepA, necessary for SPEN recruitment, are higher than in Wt blastocysts $^{37}$, which is suggestive of defective Tsix silencing in the absence of SPEN. (II) SPEN overexpression in ESCs leads to higher Xist levels and ectopic Xist cloud formation in the undifferentiated state, suggesting that SPEN overexpression might lead to partial silencing of the Tsix promoter, facilitating Xist expression. (III) SPEN binds to active promoters and enhancers to silence the $\mathrm{X}$ chromosome ${ }^{25}$. Spatial proximity to the Xist locus is a strong predictor of X-linked gene silencing efficiency ${ }^{26,38}$. One of the closest actively transcribed promoters to Xist is Tsix and we indeed observe SPEN binding at the Tsix regulatory region. (IV) Spen ${ }^{-1-}$ cell lines cannot upregulate Xist, while compound Spen:Tsix defective cell lines (Spen ${ }^{-1-}:$ Tsix-Stop) display normal Xist levels upon differentiation, indicating that in the absence of SPEN, Tsix, which acts as a brake on Xist transcription, cannot be silenced. Furthermore, our results show that SPEN plays a role in Xist stability, both upon forced Xist upregulation in undifferentiated ESCs and in differentiating Tsix-Stop ESCs, in line with a recently published study, where a role for SPEN in RNA Xist stability is described using microscopy-based approaches $^{39}$.

During initiation of XCI, when Xist starts to be transcribed from the future $\mathrm{Xi}$, SPEN helps remodel the chromatin environment of the Xist-Tsix locus. SPEN and HDAC3 are present at the Tsix regulatory region and $\mathrm{H} 3 \mathrm{~K} 27 \mathrm{ac}$ levels decrease upon Xist induction. Accordingly, we propose that during XCI initiation, SPEN binds Xist nascent transcripts ${ }^{25}$, recruits and/or activates HDAC $3^{16,29}$, which removes histone acetylation marks, weakening the Tsix promoter activity and facilitating Xist expression. Then, Xist spreads together with SPEN along the X-chromosome to silence active genes. Moreover, SPEN is necessary for Xist RNA stabilization (Fig. 7).

The mechanism driving the symmetry breaking event leading to monoallelic upregulation of Xist has been a focus of many 
studies. Several studies showed that the Xic and more specifically the Xist-Tsix master switch are tightly regulated in a deterministic process, involving monoallelic downregulation of Tsix or $\mathrm{X}$-pairing mechanisms ${ }^{40-42}$. In contrast, our studies, and studies of others, indicate that a gene regulatory network composed of transacting activators and inhibitors of XCI, involving positiveand negative-feedback loops, instructs the cis-regulatory landscape of the Xic to direct monoallelic upregulation of Xist $t^{12,34,43,44}$. Tsix silencing not only involves downregulation of inhibitors of XCI, including pluripotency factors OCT4, SOX2, KLF4, c-MYC, and REX1 ${ }^{45-47}$, but also involves Xist-mediated recruitment of SPEN as our present work reveals. This can happen on either allele, but asynchronous Xist transcription bursts will facilitate Xist-mediated monoallelic silencing of Tsix through SPEN, resulting in further upregulation of Xist and concomitant silencing of the XCI activator Rnf12, providing a negative feedback loop to prevent upregulation of Xist on the future active $\mathrm{X}$ chromosome. In humans, SPEN seems to play a role in $\mathrm{XCI}^{48}$ even though in-depth mechanistic studies are missing, but whether SPEN is required for XIST upregulation is unknown. In addition, TSIX does not completely overlap XIST and does not seem to be a strong regulator of XIST ${ }^{49,50}$, therefore, a mechanism in which SPEN negatively regulates TSIX to allow XIST upregulation is not very likely. However, the possibility that SPEN controls other human-specific XIST regulators should be taken into consideration.

\begin{abstract}
Methods
Cell culture. Mouse ESCs were grown on feeder cells, Wt C57BL/6 male-irradiated mouse embryonic fibroblasts (MEFs), and medium containing DMEM (Gibco, $11995065), 15 \%$ fetal calf serum (FCS) (Capricorn Scientific, FBS-12A), $0.1 \mathrm{mM}$ nonessential amino acids (NEAA) (Lonza, BE13-114E), $100 \mathrm{U} \mathrm{mL}^{-1}$ penicillin, 100 ug $\mathrm{mL}^{-1}$ streptomycin (Sigma-Aldrich, P0781), $0.1 \mathrm{mM}$ 2-mercaptoethanol (Gibco, 31350010) and $5.000 \mathrm{U} \mathrm{mL}^{-1}$ LIF. Previous to monolayer differentiation cells were plated in nongelatinized plates to eliminate feeder cells. Then, plated at specific densities per time point in differentiation medium composed of IMDMglutamax (Gibco, 31980030), 15\% FCS, $0.1 \mathrm{mM} \mathrm{NEAA,} 100 \mathrm{U} \mathrm{mL}^{-1}$ penicillin, $100 \mu \mathrm{g} \mathrm{mL}^{-1}$ streptomycin, $37.8 \mu \mathrm{L} \mathrm{L}^{-1}$ monothioglycerol (Sigma-Aldrich, M6145) and $50 \mu \mathrm{g} \mathrm{mL}^{-1}$ ascorbic acid (Sigma-Aldrich, A92902). When appropriate, the medium was supplemented with $2 \mu \mathrm{g} \mathrm{mL}^{-1}$ doxycycline (Sigma-Aldrich, D9891).
\end{abstract}

\section{Gene editing using the CRISPR/Cas9 technology. Different female F1 2-1} hybrid (129/Sv-Cast/Ei) ESC lines with different genetic modifications to interrogate various aspects of XCI were targeted in this study (Supplementary Table 2). To generate Spen heterozygous and homozygous knockout clones two single-guide RNAs (sgRNA) targeting the $5^{\prime}$ (5'-AGTGCGCTTCGTCACTGCAC- $\left.3^{\prime}\right)$ and $3^{\prime}\left(5^{\prime}\right.$ TCCTCCCGCCCCGACGCGGA-3') region of the Spen ORF were cloned in the Cas9-GFP pX458 vector (Addgene plasmid \#48138). Compatible 5' and $3^{\prime}$ homology arms (HA) of approximately $500 \mathrm{bp}$ were amplified by PCR from mouse gDNA and cloned in the pCR-Blunt-II-TOPO vector with a NdeI restriction site in-between the $5^{\prime}$ and $3^{\prime}$ HA. This site was used to insert a puromycin resistance (PuroR) cassette flanked by loxP sites. The ROSA26 locus was targeted using the pX458 vector coding for a sgRNA (5'-CGCCCATCTTCTAGAAAGAC-3') compatible with the pFD46 expression vector ${ }^{25}$, coding for the Spen cDNA and a hygromycin resistance cassette. To create an endogenous Spen C-terminal enhanced GFP (eGFP) knock-in, a sgRNA targeting the $3^{\prime}$ end of Spen ORF ( $5^{\prime}-$ ATTGTCATTGCCTCGGTGTG-3') was cloned in the Cas9-PuroR pX459 vector (Addgene plasmid \#62988). The donor template was made using a gblock from Integrated DNA Technologies coding for compatible $5^{\prime}$ and $3^{\prime} \mathrm{HA}$ of $600 \mathrm{bp}$ with a NheI and AscI restrictions sites in-between the $5^{\prime}$ and $3^{\prime} \mathrm{HA}$, which were used to insert an eGFP in frame with the Spen coding sequence. To clone the sgRNAs, two complementary oligonucleotides coding for the desired target sequence and overhangs compatible with the restriction enzyme BsbI were annealed and ligated in the pX458 or px459 plasmids, that were previously digested with BsbI. The appropriate plasmid combinations were transfected into ESCs using Lipofectamine 2.000 (Invitrogen, 11668019) and plated at low density to obtain single colonies, when the appropriate medium was supplemented with $1 \mu \mathrm{g} \mathrm{m}^{-1}$ puromycin (Sigma-Aldrich, P8833) for $48-72 \mathrm{~h}$ or $250 \mu \mathrm{g} \mathrm{mL}^{-1}$ hygromycin B (Invitrogen, 10687010) for 7 days. Colonies were screened by PCR for correct integration of the desired construct (Supplementary Table 3). Positive clones were further characterized by Western blot, RT-qPCR and/or FACS, and the presence of $2 \mathrm{X}$ chromosomes and correct karyotype was also assessed. Full scan images of all the genotyping gels are available in the Source Data file.
Protein extraction and Western blot. To prepare nuclear extracts all procedures were done at $4^{\circ} \mathrm{C}$ and buffers supplemented with $1 \mathrm{x}$ protease inhibitors (Roche, 4693132001), $15 \mu \mathrm{M}$ MG-132 (Sigma-Aldrich, C2211) and 0.5 mM DTT. Cells were harvested by scraping in cold PBS, collected and centrifuged $(200 \times g, 5 \mathrm{~min}$, $\left.4^{\circ} \mathrm{C}\right)$. The pellet was incubated in $5 \mathrm{x}$ the pellet volume of Buffer $\mathrm{A}(10 \mathrm{mM}$ Hepes $\mathrm{pH} 7.6,1.5 \mathrm{mM} \mathrm{MgCl}_{2}$, and $10 \mathrm{mM} \mathrm{KCl}$ ) for $10 \mathrm{~min}$, vortexed (30 sec) and centrifuged $\left(900 \times g, 5 \mathrm{~min}, 4^{\circ} \mathrm{C}\right)$. Then, the pellet was resuspended in 1.5x Buffer $\mathrm{C}$ (20 mM Hepes pH 7.6, 25\% glycerol, $420 \mathrm{mM} \mathrm{NaCl}, 1.5 \mathrm{mM} \mathrm{MgCl}$, and $0.2 \mathrm{mM}$ EDTA $)$ and rotated $\left(30 \mathrm{~min}, 4^{\circ} \mathrm{C}\right)$. The solution was centrifuged $(18,000 \times g$, $10 \mathrm{~min}, 4^{\circ} \mathrm{C}$ ) and the supernatant collected as nuclear extract. The protein concentration was measured using Nanodrop and all samples diluted to the same concentration using Buffer C. NuPAGE ${ }^{\mathrm{m}}$ LDS Sample Buffer (4X) (Invitrogen, NP0007) containing 5\% b-mercaptoethanol was added to nuclear extracts, and boiled $\left(95^{\circ} \mathrm{C}, 5 \mathrm{~min}\right)$. For Western blot analysis, the NuPAGE${ }^{\mathrm{m}} 3-8 \%$ Tris-Acetate gels (Invitrogen, EA03755) were used with Tris-Acetate SDS Running Buffer ( $\mathrm{pH}$ 8.24) (Invitrogen, LA0041) and the HiMark Pre-Stained Protein Standard (Invitrogen, LC5699). Wet transfer on a PVDF membrane was done overnight at $40 \mathrm{~mA}$, with the NuPAGE ${ }^{\mathrm{mm}}$ Transfer Buffer (Invitrogen, NP00061), containing 10\% methanol and $0.1 \%$ SDS. After blocking, the membrane was incubated with the appropriate primary antibodies, SPEN antibody (Abcam, ab72266, 1:2.000), AntiFlag antibody M2-Peroxidase (Sigma-Aldrich, A8592, 1:3.000) and/or VCP antibody (Abcam, ab11433, 1:20.000), and appropriate secondary antibodies, IRDye 800CW donkey-anti-rabbit (LI-COR Biosciences, P/N 925-32213, 1:10.000), IRDye 680RD donkey-anti-mouse (LI-COR Biosciences, P/N 925-68072, 1:15.000) and/or Goat anti-mouse-Peroxidase antibody (Sigma-Aldrich, A4416, 1:4.000). Full scan images of all the Western blots are available in the Source Data file.

RT-qPCR. Total RNA was isolated from cell pellets using the ReliaPrep RNA Cell Miniprep System (Promega, Z6012) and reversed-transcribed using Superscript III (Invitrogen, 18080093) and random hexamers (Invitrogen, N8080127), following the manufacturer's instructions. All RT-qPCRs were done using the GoTaq qPCR Master Mix (Promega, A6002) in a CFX384 real-time PCR-detection system (BioRad). Hist2h2aal was used as a normalization control, except in the RNA-stability assays where Beta-actin was used. All expression primers are listed in Supplementary Table 4 . The optimal allele-specific primer-pair concentration to amplify the 129 and Cast allele at the same efficiency was optimized using pure 129, Cast and 129-Cast gDNA.

RNA-stability assay. To study the Xist RNA stability in undifferentiated ESCs, Wt and Spen ${ }^{-1-}$ ESC lines with a doxycycline-responsive Xist promoter were cultured in ESC medium supplemented with doxycycline to induce Xist expression for four days. While in doxycycline treatment, $5 \mu \mathrm{g} \mathrm{mL}^{-1}$ actinomycin D (Sigma-Aldrich, A1410) was added for different time $(t=0,2,6$, and $10 \mathrm{~h})$. Before collection, ESCs were plated in nongelatinized plates to remove the feeders. To study the Xist RNA stability in differentiating Wt and Spen ${ }^{-1-}$ Tsix-Stop ESCs, cells were differentiated, as explained in the "Cell culture" methods section, and $5 \mu \mathrm{g} \mathrm{mL} \mathrm{L}^{-1}$ actinomycin $\mathrm{D}$ were added for different time $(t=0,2,4,6$, and $10 \mathrm{~h})$. In both cases, cells were harvested for RNA isolation, cDNA synthesis and RT-qPCR. Then, total Xist levels were determined and normalized to Beta-actin and the percentage of the remaining Xist RNA was calculated by dividing Xist expression levels at the different times of collection relative to $t=0$. Using linear regression analysis the RNA decay rate constant $\left(k_{\text {decay }}\right)$ was calculated from the slope of the curve that best fitted our data and the RNA half-life $\left(t_{1 / 2}\right)$ obtained with the following formula $t_{1 / 2}=\frac{\ln 2}{k \text { decay }}$.

Immunofluorescence (IF). Undifferentiated ESCs were attached to slides using a cytospin, while differentiating cells were grown on coverslips coated with gelatin (Sigma-Aldrich, G1890) or laminin (Sigma-Aldrich, L2020). Cells were fixed with $4 \%$ paraformaldehyde (PFA) in PBS (10 min, RT), permeabilized with $0.4 \%$ Triton$\mathrm{X} 100$ and $5 \%$ goat serum in PBS ( $15 \mathrm{~min}$, on ice) and blocked with $10 \%$ goat serum in PBST, composed of $0.05 \%$ Tween-20 in PBS (30 min, RT). Primary antibody incubation was done in blocking buffer ( $2 \mathrm{~h}, \mathrm{RT})$, after three washings with PBST the slides were incubated with the secondary antibody $(1 \mathrm{~h}, \mathrm{RT})$. After three washings, the second washing containing DAPI, the slides were mounted with ProLong Gold antifade mounting medium (Invitrogen, P36930). The used primary antibodies were the following: aGFP (Abcam, ab290, 1:500), H3K27me2/3 (Active motif, 39535, 1:100) and EZH2 (BD43 clone, kindly provided by Dr. Kristian Helin, 1:100). The used secondary antibodies were Goat-anti-Rabbit-488 (Invitrogen, A-11008 1:1.000) and Goat-anti-Mouse-546, (Invitrogen, A-1103, 1:400). Images were taken using a ZEISS Axio Imager M2 including digital microscopy camera AxioCam 503 and analyzed with ImageJ. To quantify the intensity of the SPENGFP accumulation at different days of monolayer differentiation, we determined the mean intensity of a region of interest (ROI) covering a specific SPEN-GFP accumulation. Next, this value was normalized to the mean nuclei background intensity excluding the SPEN-GFP ROI, calculated as the average intensity of 10 different nuclei per image.

IF combined with RNA fluorescent in situ hybridization (FISH). The Xist FISH probe was made from $2 \mu \mathrm{g}$ of a $5.5 \mathrm{~kb}$ DNA fragment of mouse Xist comprising 
exons 3-7. Fluorescent labeling was done with dUTP SpectrumRed using the nick translation kit (Abbott, $07 \mathrm{~J} 00-001$ ) overnight at $16^{\circ} \mathrm{C}$. The probe was purified with ProbeQuant G-50 Micro Columns (GE, GE28-9034-08), combined with $100 \mu \mathrm{g}$ of mouse tRNA, $20 \mu \mathrm{g}$ of mouse Cot-1 DNA (Invitrogen, 18440-016) and $100 \mu \mathrm{g}$ of salmon sperm DNA (Invitrogen, 15632-011) and precipitated with $2 \mathrm{M} \mathrm{NaAc}(\mathrm{pH}$ 5.6) and $100 \% \mathrm{EtOH}$. The pellet was resuspended in $50 \mu \mathrm{L}$ hybridization mix $(50 \%$ formamide, $10 \%$ dextran sulfate in $2 \mathrm{xSSC}$ ) and stored at $-20^{\circ} \mathrm{C}$. Before use, $20 \mu \mathrm{L}$ of probe was prehybridized $\left(10 \mathrm{~min}, 75^{\circ} \mathrm{C}\right)$ with $0.5 \mu \mathrm{g}$ of mouse Cot-1 DNA supplemented with $10 \mathrm{mM}$ vanadyl ribonucleoside complex (VRC) (NEB, S1402S)

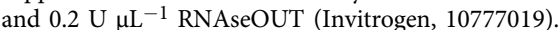

Cells on coverslips or slides were fixed with 4\% PFA in PBS (10 min, RT), permeabilized with $0.5 \%$ Triton-X100 in PBS and blocked in TS-BSA buffer $(0.1 \mathrm{M}$ Tris- $\mathrm{HCl}$ (pH 7.5), $0.15 \mathrm{M} \mathrm{NaCl}$, and $2 \mathrm{mg} \mathrm{mL}^{-1} \mathrm{BSA}$ (Jena Bioscience, $\mathrm{BU}-102$ ) in $\mathrm{H}_{2} \mathrm{O}$ ). The aGFP (Abcam, ab290, 1:500) primary antibody was incubated in blocking buffer $\left(30 \mathrm{~min}, 37^{\circ} \mathrm{C}\right)$, washed in PBS $(3 \mathrm{x})$ and then incubated with the secondary antibody $\left(30 \mathrm{~min}, 37^{\circ} \mathrm{C}\right)$. All solutions were supplemented with $10 \mu \mathrm{M}$

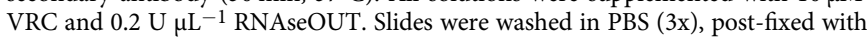
$4 \%$ PFA (10 min, RT), and washed again in PBS (x3). Dehydration was done with increasing ethanol concentrations $(70 \%, 90 \%$ and $100 \%)$. The prehybridized probe was added on top of the coverslips or slides $\left(20 \mathrm{~h}, 37^{\circ} \mathrm{C}\right.$, humid chamber). Various washings were done with $50 \%$ formamide $/ 2 \mathrm{x} \mathrm{SSC}\left(5 \mathrm{~min}, 37^{\circ} \mathrm{C}, 2 \mathrm{x}\right), 2 \mathrm{x} \mathrm{SSC}(5 \mathrm{~min}$, $\left.37^{\circ} \mathrm{C}, 2 \mathrm{x}\right)$ and TS buffers $(5 \mathrm{~min}, \mathrm{RT}, 2 \mathrm{x})$. Then the slides were mounted and visualized as explained in the "IF" section.

FISH. The FISH only protocol was done as described in the IF-FISH section, skipping the IF section. Directly after the permeabilization, the dehydration step was performed.

RNA-seq. Doxycycline treated cells were sorted to isolate dsRed positive cells upregulating Xist from the desired allele. RNA was isolated using the ReliaPrep RNA Cell Miniprep System. A total of 16 DNA libraries were created, a maximum of $1 \mathrm{ng}$ of total RNA was used following the Smart-seq2 protocol $^{51}$ without modifications. Then, we used the Nextera DNA Flex library prep kit (Illumina) to create a library from full-length cDNA. Samples were sequenced on a HiSeq2500 sequencer (50 bp single-end reads).

Chromatin immunoprecipitation (ChIP)-seq. In total, $50 \times 10^{6}$ cells were trypsinized, resuspended and fixed in $50 \mathrm{~mL}$ of warm medium and $1 \%$ PFA for $10 \mathrm{~min}$ at $37^{\circ} \mathrm{C}$. About $2.5 \mathrm{~mL}$ of Glycine $2.5 \mathrm{M}$ were added to the cells (final concentration $0.125 \mathrm{M}$ ) to quench the PFA, 5 min RT on a rotator. All buffers from now on contain protease inhibitors (Roche, 4693132001). Cells were washed twice with cold PBS. Then $1 \mathrm{x}$ in $10 \mathrm{~mL}$ of Buffer 1 (10 mM Hepes pH 7.5, $10 \mathrm{mM}$ EDTA, $0.5 \mathrm{mM}$ EGTA, and $0.75 \%$ Triton X-100) and $1 \mathrm{x}$ in Buffer $2(10 \mathrm{mM}$ Hepes pH 7.5, $200 \mathrm{mM} \mathrm{NaCl}, 1 \mathrm{mM}$ EDTA, $0.5 \mathrm{mM}$ EGTA), $10 \mathrm{~min}$ rotating at $4^{\circ} \mathrm{C}$. Nuclei were then resuspended in Lysis/Sonication Buffer $(150 \mathrm{mM} \mathrm{NaCl}, 25 \mathrm{mM}$ Tris-HCl $\mathrm{pH}$ 7.5, 5 mM EDTA, $1 \%$ Triton, $0.1 \%$ SDS, $0.5 \%$ Sodium deoxycholate) and incubated for $30 \mathrm{~min}$ on ice. Nuclei were then sonicated $2 \times 15 \mathrm{~min}\left(30^{\prime \prime} \mathrm{ON} / \mathrm{OFF}\right.$, max input, ice cold water) in a Bioruptor. A small fraction of the lysate was run on a gel to confirm size population of 100-500 bp. About $1 \mu \mathrm{g}$ of H3K27me3 antibody (Cell Signaling, 9733 S) was conjugated with $25 \mu \mathrm{L}$ of magnetic beads (Life Technologies, $10004 \mathrm{D}$ ) for $3 \mathrm{~h}$ rotating at $4^{\circ} \mathrm{C}$. About 25 ug of chromatin was IP'd with the $\mathrm{Ab}$ beads overnight rotating at $4^{\circ} \mathrm{C}$. Beads were washed $2 \mathrm{x}$ in standard RIPA buffer $(140 \mathrm{mM} \mathrm{NaCl}, 10 \mathrm{mM}$ Tris-HCl pH $7.5150 \mathrm{mM} \mathrm{NaCl}, 1 \mathrm{mM}$ EDTA pH8.0, 0.5 mM EGTA pH 8.0, $1 \%$ Triton, $0.1 \%$ SDS, $0.5 \%$ Sodium deoxycholate), and $1 \mathrm{x}$ in High Salt RIPA (same as standard RIPA but with $500 \mathrm{mM} \mathrm{NaCl}$ ), 1x LiCl RIPA (same as standard RIPA but with $250 \mathrm{mM} \mathrm{LiCl}$ instead of $\mathrm{NaCl}$ ) and rinsed once with TE, $10 \mathrm{~min} 4^{\circ} \mathrm{C}$ each wash. Chromatin was eluted with $450 \mu \mathrm{L}$ of Elution Buffer ( $1 \%$ SDS; $0.1 \mathrm{M} \mathrm{NaHCO}_{3}$ in $\left.\mathrm{H}_{2} \mathrm{O}\right)$ with $22 \mu \mathrm{L}$ protease $\mathrm{K}\left(10 \mathrm{mg} \mathrm{mL}^{-1}\right)$ and $5 \mu \mathrm{L}$ RNAse A $\left(10 \mathrm{mg} \mathrm{mL}^{-1}\right)$ and shaken at $1,000 \mathrm{rpm}$ on an orbital thermal-mixer for $2 \mathrm{~h}$ at $37^{\circ} \mathrm{C}$ first and then $65^{\circ} \mathrm{C}$ overnight. DNA was then Phenol-Chloroform extracted and resuspended in $20 \mu \mathrm{L}$ of $\mathrm{H}_{2} \mathrm{O}$. About $0.25 \mu \mathrm{L}$ was used per PCR to confirm the ChIP's success. The concentration was then measured and a ChIP-seq library was prepared using the ThruPLEX DNA-Seq Kit (Takara Bio, R400675), by following the manufacturer's instructions: template preparation to obtain a homogeneous double-stranded DNA material, library synthesis to ligate stem-loop adapters and a final library amplification step to extend the template, remove the stem-loop adapters and amplify the library for posterior sequencing on an Illumina HiSeq 2500 sequencer (50 bp paired-end reads).

NGS data analysis: allele-specific RNA-seq and ChIP-seq. Both the RNA-sec and the ChIP-seq data were processed allele-specifically. The single nucleotide polymorphism (SNPs) in the 129/Sv and Cast/Ei lines was downloaded from the Sanger institute (v.5 SNP142) ${ }^{52}$. These were used as input for SNPsplit v0.3.4 $4^{53}$, to construct an $\mathrm{N}$-masked reference genome based on mm10 in which all SNPs between 129/Sv and Cast/Ei were masked. The $50 \mathrm{bp}$ single-end RNA-seq and 50 bp paired-end ChIP-seq reads were mapped to this $\mathrm{N}$-masked reference genome using the default settings of hisat2 v2.2.1 and bowtie2 v2.4.1, respectively54,55. SNPsplit (--paired for the ChIP-seq analysis) was then used to assign the reads to either the $129 / \mathrm{Sv}$ or Cast/Ei bam file based on the best alignment or to a common bam file if mapping to a region without allele-specific SNPs. The allele-specific and unassigned bam files were sorted using samtools v1.1056.

For the RNA-seq, the number of mapped reads per gene were counted for both alleles separately using HTSeq v0.12.4 (--nonunique=none $-\mathrm{m}$ intersectionnonempty $)^{57}$ based on the gene annotation from ensembl v98. For each condition, genes with more than 20 allele-specific reads across both replicates were used to calculate the allelic ratio, defined as $\left(\frac{X i}{X i+X a}\right)$. For day 0 and day 7 , Cast/Ei and 129/ $\mathrm{Sv}$ were used as the Xi and active allele (Xa), respectively, whereas for day 3, Cast/E and $129 / \mathrm{Sv}$ were used as $\mathrm{Xa}$ and $\mathrm{Xi}$, respectively. The allelic ratios of X-linked genes were visualized as violin plots with boxplots of the same data on top. Significant differences between conditions were tested using a two-sided Mann-Whitney test with $\alpha<0.05$. P-values were corrected for multiple testing using the Benjamini-Hochberg procedure. Different conditions were compared by plotting the X-linked genes that had more than 20 allele-specific reads in both conditions along the $\mathrm{X}$ chromosome. A two-sided Wilcoxon signed-rank test with $\alpha<0.05$ was used to test for significant differences between the allelic ratios of the different conditions, after which P-values were corrected for multiple testing using the Benjamini-Hochberg procedure. We visualized differences in allelic ratios of $\mathrm{X}$-linked genes between conditions by plotting both ratios on the different axes of a scatter plot. Genes were highlighted when they were identified as lowly silenced genes in Spen ${ }^{-1-}$ ESCs from ${ }^{27}$, which were defined as genes showing $-0.05<\mathrm{z}<-$ 0.2 where $\mathrm{z}$ (gene silencing) $=\left(\frac{X i}{X i+X a}\right) d o x-\left(\frac{X i}{X i+X a}\right)$ noDox.

The allele-specific ChIP-seq bam files were normalized using the 'callpeak' and 'bdgcmp' functions of MACS2 v2.2.7.158. We called broad peaks (-f BAMPE --broad --bdg) and used the Poisson P-value as the method for normalizing the tracks. The input-normalized tracks were visualized using pyGenomeTracks v3.4. ${ }^{59}$. For validation, we downloaded several publicly available datasets. The SPEN CUT\&RUN data (GSE131782, samples: SRX5903674, SRX5903675, SRX5903676, SRX5903677, SRX5903678, SRX5903679, SRX5903682, and SRX5903683) ${ }^{25}$, were processed similar to our analysis using a C57BL/6NJ-Cast/Ei reference genome. However, the allelespecific tracks were normalized based on the total number of mapped reads per sample. The scaling factor was calculated as $10^{\wedge} 6$ / total number of mapped reads and used as parameter --scaleFactor to both allelic tracks using deepTools bamCoverage v3.5.0.60. A binsize of 1 was used and paired-end reads were extended. The allele-specific tracks from HDAC3 and H3K27Ac (GSE116990, samples: SRX4384412, SRX4384420, SRX4384476, SRX4384484, SRX4887836, and SRX4887839) were downloaded from ${ }^{29}$ For all datasets, replicates for each condition were averaged using deepTools bigwigCompare v.3.5.0 with the settings '--operation mean --binSize $1^{\prime 60}$. In the genome browser overview showing the allele-specific tracks, the y axis was scaled for each group of samples separately.

Reporting summary. Further information on research design is available in the Nature Research Reporting Summary linked to this article.

\section{Data availability}

All raw and processed high-throughput sequencing data (ChIP-seq, RNA-seq) generated in this study have been submitted to the NCBI Gene Expression Omnibus (GEO) under accession number GSE163321. All other relevant data are available in the Supplementary Information, Source Data file, or from the corresponding author upon request. We used data from the following publicly available datasets: GSE131782 and GSE116990. Source data are provided with this paper.

Received: 31 December 2020; Accepted: 8 November 2021; Published online: 01 December 2021

\section{References}

1. Lyon, M. F. Gene Action in the X-chromosome of the Mouse (Mus musculus L.). Nature 190, 372-373 (1961)

2. Borsani, G. et al. Characterization of a murine gene expressed from the inactive X chromosome. Nature 354, 56-58 (1991).

3. Brockdorff, $\mathrm{N}$. et al. Conservation of position and exclusive expression of mouse Xist from the inactive X chromosome. Nature 351, 329-331 (1991).

4. Brockdorff, $\mathrm{N}$. et al. The product of the mouse Xist gene is a $15 \mathrm{~kb}$ inactive $\mathrm{X}$-specific transcript containing no conserved ORF and located in the nucleus. Cell 71, 515-526 (1992).

5. Lee, J. T., Davidow, L. S. \& Warshawsky, D. Tsix, a gene antisense to Xist at the X-inactivation centre. Nat. Genet. 21, 400-404 (1999).

6. Stavropoulos, N., Lu, N. \& Lee, J. T. A functional role for Tsix transcription in blocking Xist RNA accumulation but not in X-chromosome choice. Proc. Natl Acad. Sci. USA 98, 10232-10237 (2001).

7. Luikenhuis, S., Wutz, A. \& Jaenisch, R. Antisense transcription through the Xist Locus mediates Tsix function in embryonic stem cells. Mol. Cell. Biol. 21, 8512-8520 (2001).

8. Shibata, S. \& Lee, J. T. Tsix Transcription- versus RNA-based mechanisms in Xist repression and epigenetic choice. Curr. Biol. 14, 1747-1754 (2004). 
9. Sado, T., Hoki, Y. \& Sasaki, H. Tsix silences Xist through modification of chromatin structure. Dev. Cell 9, 159-165 (2005).

10. Navarro, P., Pichard, S., Ciaudo, C., Avner, P. \& Rougeulle, C. Tsix transcription across the Xist gene alters chromatin conformation without affecting Xist transcription: implications for X-chromosome inactivation. Genes Dev. 19, 1474-1484 (2005).

11. Sun, B. K., Deaton, A. M. \& Lee, J. T. A transient heterochromatic state in Xist preempts X inactivation choice without RNA stabilization. Mol. Cell 21, 617-628 (2006).

12. Mutzel, V. et al. A symmetric toggle switch explains the onset of random $\mathrm{X}$ inactivation in different mammals. Nat. Struct. Mol. Biol. https://doi.org/ 10.1038/s41594-019-0214-1 (2019).

13. Mutzel, V. \& Schulz, E. G. Dosage Sensing, threshold responses, and epigenetic memory: a systems biology perspective on random X-chromosome inactivation. BioEssays 42, 1-14 (2020).

14. Loda, A. \& Heard, E. Xist RNA in action: past, present, and future. PLoS Genet. 15, 1-17 (2019).

15. Brockdorff, N. \& Turner, B. M. Dosage compensation in mammals. Cold Spring Harb. Perspect. Biol. 7, a019406 (2015).

16. McHugh, C. A. et al. The Xist lncRNA interacts directly with SHARP to silence transcription through HDAC3. Nature 521, 232-236 (2015).

17. Chu, C. et al. Systematic discovery of Xist RNA binding proteins. Cell 161, 404-416 (2015).

18. Minajigi, A. et al. A comprehensive Xist interactome reveals cohesin repulsion and an RNA-directed chromosome conformation. Science, 10.1126/ science.aab2276 (2015)

19. Monfort, A. et al. Identification of Spen as a crucial factor for Xist function through forward genetic screening in haploid embryonic stem cells. Cell Rep. 12, 554-561 (2015).

20. Moindrot, B. et al. A pooled shRNA screen identifies Rbm15, Spen, and Wtap as factors required for Xist RNA-mediated silencing. Cell Rep. 12, 562-572 (2015).

21. Ariyoshi, M. \& Schwabe, J. W. R. A conserved structural motif reveals the essential transcriptional repression function of spen proteins and their role in developmental signaling. Genes Dev. 17, 1909-1920 (2003).

22. Oswald, F. et al. A phospho-dependent mechanism involving NCoR and KMT2D controls a permissive chromatin state at Notch target genes. Nucleic Acids Res. 44, 4703-4720 (2016)

23. Shi, Y. et al. Sharp, an inducible cofactor that integrates nuclear receptor repression and activation. Genes Dev. 15, 1140-1151 (2001).

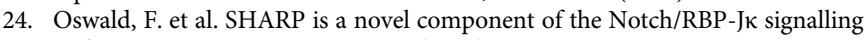
pathway. EMBO J. 21, 5417-5426 (2002).

25. Dossin, F. et al. SPEN integrates transcriptional and epigenetic control of X-inactivation. Nature 578, 455-460 (2020).

26. Loda, A. et al. Genetic and epigenetic features direct differential efficiency of Xist-mediated silencing at X-chromosomal and autosomal locations. Nat. Commun. 8, 690 (2017).

27. Nesterova, T. B. et al. Systematic allelic analysis defines the interplay of key pathways in X chromosome inactivation. Nat. Commun. 10, 1-15 (2019)

28. Ogawa, Y. \& Lee, J. T. Xite, X-inactivation intergenic transcription elements that regulate probability of choice. Mol. Cell 11, 731-743 (2003).

29. Żylicz, J. J. et al. The implication of early chromatin changes in X chromosome inactivation. Cell 176, 182-197.e23 (2019).

30. Jonkers, I. et al. RNF12 Is an X-encoded dose-dependent activator of X chromosome inactivation. Cell 139, 999-1011 (2009).

31. Heard, E. et al. Methylation of histone H3 at Lys-9 Is an early mark on the X chromosome during X inactivation. Cell 107, 727-738 (2001).

32. Rougeulle, C. et al. Differential histone H3 Lys-9 and Lys-27 methylation profiles on the X chromosome. Mol. Cell. Biol. 24, 5475-5484 (2004)

33. Loos, F. et al. Xist and Tsix transcription dynamics is regulated by the X-toautosome ratio and semistable transcriptional states. Mol. Cell. Biol. 36, 2656-2667 (2016).

34. Monkhorst, K., Jonkers, I., Rentmeester, E., Grosveld, F. \& Gribnau, J. X Inactivation counting and choice is a stochastic process: evidence for involvement of an X-linked activator. Cell 132, 410-421 (2008).

35. Carter, A. C. et al. Spen links rna-mediated endogenous retrovirus silencing and $\mathrm{x}$ chromosome inactivation. eLife 9, 1-58 (2020).

36. Kuroda, K. et al. Regulation of marginal zone B cell development by MINT, a suppressor of Notch/RBP-J signaling pathway. Immunity 18, 301-312 (2003).

37. Hoki, Y. et al. A proximal conserved repeat in the Xist gene is essential as a genomic element for X-inactivation in mouse. Development 136, 139-146 (2009).

38. Engreitz, J. M. et al. The Xist lncRNA exploits three-dimensional genome architecture to spread across the X chromosome. Science 341, 1237973 (2013).

39. Rodermund, L. et al. Time-resolved structured illumination microscopy reveals key principles of Xist RNA spreading. Science 372, eabe7500 (2021).
40. Lee, J. T. \& Lu, N. Targeted mutagenesis of Tsix leads to nonrandom X inactivation. Cell 99, 47-57 (1999).

41. Xu, N., Tsai, C. L. \& Lee, J. T. Transient homologous chromosome pairing marks the onset of X inactivation. Science 311, 1149-1152 (2006).

42. Aeby, E. et al. Decapping enzyme 1A breaks X-chromosome symmetry by controlling Tsix elongation and RNA turnover. Nat. Cell Biol. 22, 1116-1129 (2020).

43. Gayen, S. et al. A primary role for the Tsix lncRNA in maintaining random X-chromosome inactivation. Cell Rep. 11, 1251-1265 (2015).

44. Galupa, R. et al. A conserved noncoding locus regulates random monoallelic Xist expression across a topological boundary. Mol. Cell 77, 352-367.e8 (2020).

45. Donohoe, M. E., Silva, S. S., Pinter, S. F., Xu, N. \& Lee, J. T. The pluripotency factor Oct4 interacts with Ctcf and also controls X-chromosome pairing and counting. Nature 460, 128-132 (2009).

46. Navarro, P. et al. Molecular coupling of Tsix regulation and pluripotency. Nature 468, 457-460 (2010)

47. Gontan, C. et al. RNF12 initiates X-chromosome inactivation by targeting REX1 for degradation. Nature 485, 386-390 (2012)

48. Radio, F. C. et al. SPEN haploinsufficiency causes a neurodevelopmental disorder overlapping proximal $1 \mathrm{p} 36$ deletion syndrome with an episignature of X chromosomes in females. Am. J. Hum. Genet. https://doi.org/10.1016/ j.ajhg.2021.01.015. (2021)

49. Migeon, B. R., Chowdhury, A. K., Dunston, J. A. \& McIntosh, I. Identification of TSIX, encoding an RNA antisense to human XIST, reveals differences from its murine counterpart: Implications for X inactivation. Am. J. Hum. Genet. 69, 951-960 (2001).

50. Migeon, B. R., Lee, C. H., Chowdhury, A. K. \& Carpenter, H. Species differences in TSIX/Tsix reveal the roles of these genes in X-chromosome inactivation. Am. J. Hum. Genet. 71, 286-293 (2002).

51. Picelli, S. et al. Smart-seq 2 for sensitive full-length transcriptome profiling in single cells. Nat. Methods 10, 1096-1100 (2013).

52. Keane, T. M. et al. Mouse genomic variation and its effect on phenotypes and gene regulation. Nature 477, 289-294 (2011).

53. Krueger, F. \& Andrews, S. R. SNPsplit: allele-specific splitting of alignments between genomes with known SNP genotypes. F1000Research 5, 1479 (2016)

54. Kim, D., Langmead, B. \& Salzberg, S. L. HISAT: A fast spliced aligner with low memory requirements. Nat. Methods 12, 357-360 (2015).

55. Langmead, B. \& Salzberg, S. L. Fast gapped-read alignment with Bowtie 2. Nat. Methods 9, 357-359 (2012)

56. Li, H. et al. The Sequence Alignment/Map format and SAMtools. Bioinformatics 25, 2078-2079 (2009).

57. Anders, S., Pyl, P. T. \& Huber, W. HTSeq-A Python framework to work with high-throughput sequencing data. Bioinformatics 31, 166-169 (2015).

58. Zhang, Y. et al. Model-based analysis of ChIP-Seq (MACS). Genome Biol. 9, R137 (2008)

59. Lopez-Delisle, L. et al. pyGenomeTracks: reproducible plots for multivariate genomic data sets. Bioinformatics https://doi.org/10.1093/bioinformatics/ btaa692. (2020).

60. Ramírez, F. et al. deepTools2: a next generation web server for deepsequencing data analysis. Nucleic Acids Res. 44, W160-W165 (2016).

\section{Acknowledgements}

We thank Anniek Meesters and Esther Sleddens-Linkels for technical help; Kristian Helin for providing the EZH2 antibody; Martine M. Jaegle for sharing with us a floxedpuromycin resistance cassette; Joana Carvalho Moreira de Mello for her input in $\mathrm{R}$ plotting; and all the members of the Erasmus MC Developmental Biology department for useful discussions. T.R.F. is supported by an Erasmus MC grant (Mrace). T.R.F., B.F.T., H.M.B., E.T., and J.G. are supported by the Oncode Institute and a ZonMW Top subsidy (91215046). B.D.G. is supported by a research grant of the University Medical Center Giessen and Marburg (UKGM) and by a Prize of the Justus Liebig University Giessen. The work was further supported by the Deutsche Forschungsgemeinschaft (DFG, German Research Foundation) - TRR 81/3-109546710 and BO1639/9-393040308, and the Von Behring-Röntgen foundation and Excellence Cluster for Cardio Pulmonary System (ECCPS) in Giessen to T.B.

\section{Author contributions}

T.R.F. and J.G. conceived the project and designed the experiments. T.R.F. and E.T. performed most of the experimental work and data analysis. H.M.B. performed the ChIP-seq experiments. B.F.T. performed all the bioinformatic analysis. C.G. helped setup the high-molecular-weight Western blot analysis. S.M. setup the allele-specific RT-qPCR analysis. B.D.G., F.D., T.B. and E.H. provided valuable resources and input. H.M.B. and J.G. supervised the work. T.R.F. and J.G. wrote the paper with input from all the authors. H.M.B. helped review and edit the paper. J.W.M.M. and J.G. were responsible for the funding acquisition. RNA-seq and ChIP-seq datasets were generated in the Erasmus MC Center for Biomics led by W.F.J.v.IJ. 


\section{Competing interests}

The authors declare no competing interests.

\section{Additional information}

Supplementary information The online version contains supplementary material available at https://doi.org/10.1038/s41467-021-27294-5.

Correspondence and requests for materials should be addressed to Joost Gribnau.

Peer review information Nature Communications thanks the anonymous reviewers for their contribution to the peer review of this work. Peer-reviewer reports are available.

Reprints and permission information is available at http://www.nature.com/reprints

Publisher's note Springer Nature remains neutral with regard to jurisdictional claims in published maps and institutional affiliations. (c) (i) Open Access This article is licensed under a Creative Commons Attribution 4.0 International License, which permits use, sharing, adaptation, distribution and reproduction in any medium or format, as long as you give appropriate credit to the original author(s) and the source, provide a link to the Creative Commons license, and indicate if changes were made. The images or other third party material in this article are included in the article's Creative Commons license, unless indicated otherwise in a credit line to the material. If material is not included in the article's Creative Commons license and your intended use is not permitted by statutory regulation or exceeds the permitted use, you will need to obtain permission directly from the copyright holder. To view a copy of this license, visit http://creativecommons.org/ licenses/by/4.0/.

(C) The Author(s) 2021 